\title{
UNIVERSIDADE DE SÃO PAULO
}

ESCOLA DE ENFERMAGEM

NANCI CRISTIANO SANTOS

CONSTRUÇÃO DE INSTRUMENTO PARA IDENTIFICAÇÃO

DA CARGA DE TRABALHO DA EQUIPE DE ENFERMAGEM

EM UNIDADES PEDIÁTRICAS

São Paulo

2006 
NANCI CRISTIANO SANTOS

CONSTRUÇÃO DE INSTRUMENTO PARA IDENTIFICAÇÃO

DA CARGA DE TRABALHO DA EQUIPE DE ENFERMAGEM EM UNIDADES PEDIÁTRICAS

Dissertação apresentada ao Programa de Pós-Graduação da Escola de Enfermagem da Universidade de São Paulo para obtenção do título de Mestre em Enfermagem.

Área de concentração:

Administração em Serviços de

Enfermagem

Orientadora:

Prof. ${ }^{a}$ Dr. ${ }^{a}$ Fernanda Maria Togeiro Fugulin

São Paulo

2006 


\section{Catalogação na Publicação (CIP) \\ Biblioteca "Wanda de Aguiar Horta" \\ Escola de Enfermagem da Universidade de São Paulo}

Santos, Nanci Cristiano.

Construção de instrumento para identificação da carga de trabalho da equipe de enfermagem em unidades pediátricas. / Nanci Cristiano Santos.

- São Paulo: N. C. Santos, 2006.

$109 \mathrm{p}$.

Dissertação (Mestrado) - Escola de Enfermagem da Universidade de São Paulo.

Orientadora: $\operatorname{Prof}^{\mathrm{a}} \mathrm{Dr}^{\mathrm{a}}$ Fernanda Maria Togeiro Fugulin

1. Administração de recursos humanos 2. Recursos humanos (Dimensionamento) 3. Enfermagem pediátrica. I. Título. 


\title{
Mensagem
}

...Quero reviver a primeira manhã da criação, o primeiro abrir dos olhos para a vida.

Quero nascer de novo a cada dia que nasce.

Quero ser outra vez novo, puro, cristalino.

Quero lavar-me a cada manhã, do homem velho, da poeira velha, das palavras gastas, dos gestos rituais.

\author{
Quero que cada manhã \\ a alma desabroche do sono \\ como a rosa do botão, e surja,
}

como a aurora do oceano, ao sorriso dos teus lábios ao gesto de tua mão.

Chico Xavier 


\section{Dedicatória...}

Aos meus pais João e Helena, pelos princípios de amor, humildade, tolerância e honestidade.

Vocês me ensinaram a acreditar na esperança de um novo amanhã.

Aos meus irmãos e cunhados, pelo apoio, amor e união à família, que me dão à certeza que não nos encontramos por acaso...

ao Cláudio, pelo incentivo apoio e exemplo de perseverança...

aos meus filhos amados, Larissa Guilherme e Gabrielle minha fonte de amor, alegria e esperança renovada a cada dia ....

Vocês são a maior razão do meu viver.....

Meu amor e carinho porque vocês me ajudam a ser o que sou... 


\section{Agradecimentos}

À Deus pela grandiosa Lei de Amor e caridade.

À Prof ${ }^{a}$ Fernanda Maria Togeiro Fugulin, pela amizade, disponibilidade, atenção e apoio, que tornaram essa caminhada tranqüila favorecendo meu crescimento profissional.

À Prof ${ }^{a}$ Raquel Gaidzinski pela confiança, incentivo constante, dinamismo e capacidade de enxergar muito adiante.

Às enfermeiras especialistas pela dedicação e preciosas sugestões que em muito contribuíram para a realização deste estudo.

Ao enfermeiros Antonio Fernandes, Prof ${ }^{a_{s}}$ Vera Lúcia, Marta e Daisy, pelas sugestões, apoio e incentivo, sempre dispostos a ajudar.

À minha chefe e amiga Alda Valéria, pessoa amiga e verdadeira, pela compreensão, apoio e confiança,

Às colegas da DEMI, Eliete, Telma, Chang e Ilva pelo apoio e amizade.

À enfermeira Karin Emilia Rogenski, pela amizade $e$ companheirismo nesta caminhada,

À todas as Enfermeiras, Técnicas/auxiliares de enfermagem $e$ equipe multidisciplinar da clínica pediátrica do HU pelo apoio, incentivo, solidariedade, compreensão e principalmente pelo profissionalismo, carinho e amor que dedicam às nossas crianças...

Vocês fazem a diferença na vida dessas crianças..

A amiga Cristiane de Lion Botero, amiga especial a quem admiro pelo otimismo altruísmo e disponibilidade em todos os momentos....

Às inúmeras amigas do HU-USP que sempre ofereceram uma palavra de incentivo. 
A Maria Alice, Nadir e Lucila das bibliotecas do HU e EEUSP pela atenção e disponibilidade na revisão bibliográfica.

À Diley e Jane pela prestimosa colaboração nos momentos finais desta dissertação.

À todos aqueles que de alguma maneira tornaram este sonho possivel... 


\section{SUMÁRIO}

Lista de Quadros

Resumo

Abstract

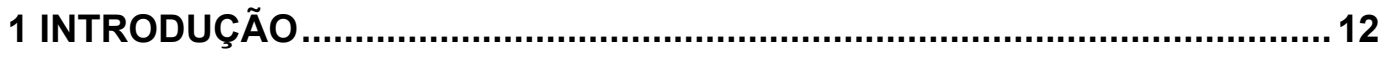

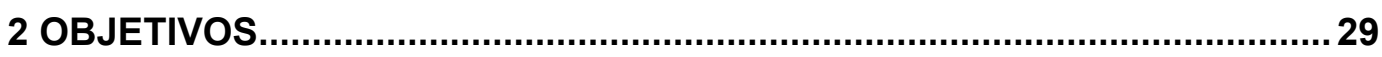

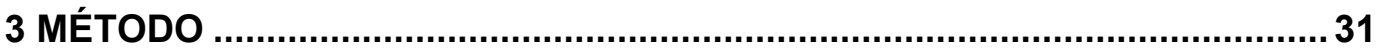

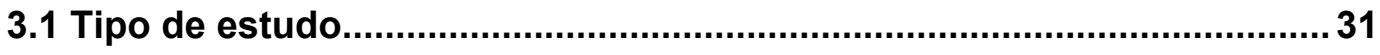

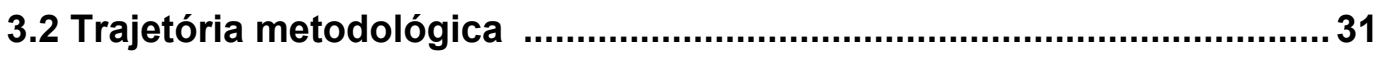

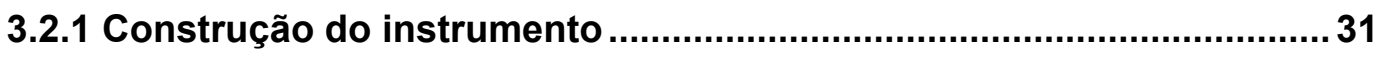

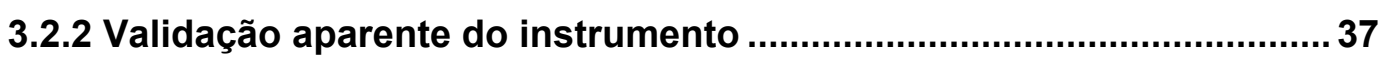

3.2.2.1 Participação dos especialistas ......................................................... 38

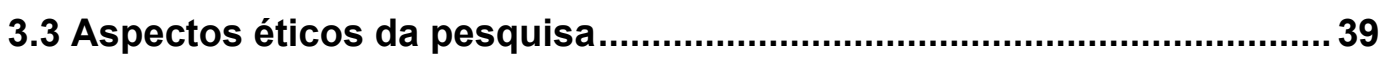

4 RESULTADOS E DISCUSSÃO ............................................................... 41

4.1 Proposta inicial do instrumento ............................................................ 41

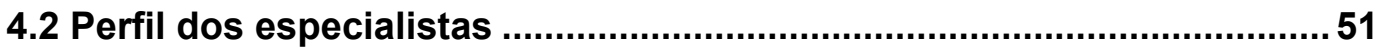

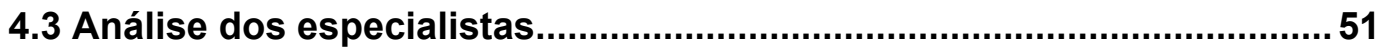

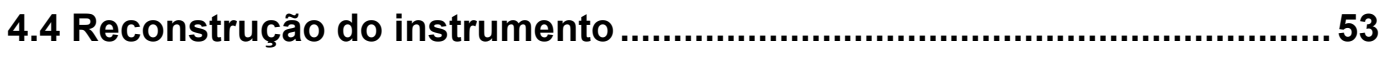

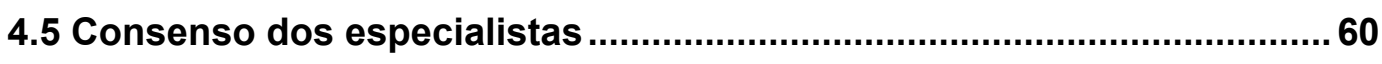

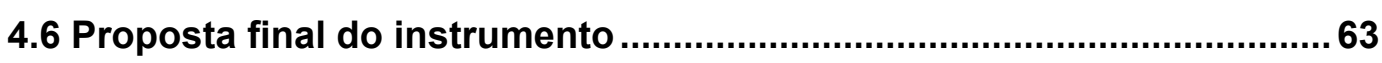

5 CONSIDERAÇÕES FINAIS.................................................................. 73

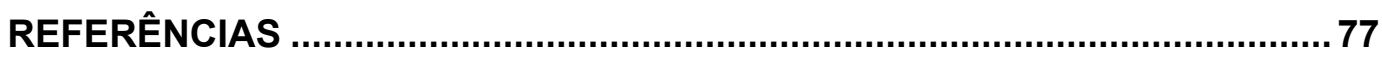

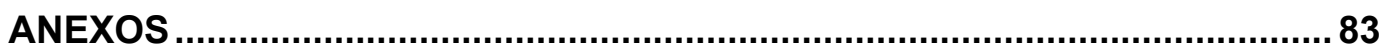




\section{LISTA DE QUADROS}

QUADRO 1 - Horas médias de assistência de enfermagem, segundo categoria de cuidado, indicadas por Alcalá et al........................................17

QUADRO 2 - Horas médias de assistência de enfermagem, segundo categoria de cuidado, estabelecidas por Alves et al.................................. 18

QUADRO 3 - Horas médias de assistência de enfermagem, segundo categoria de cuidado, estabelecidas pela Resolução COFEN n 189/96......20

QUADRO 4 - Horas médias de assistência de enfermagem, segundo categoria de cuidado, estabelecidas pela Resolução COFEN n 293/04.... 21

QUADRO 5 - Distribuição dos Domínios e Classes selecionados para composição do instrumento 
Santos NC. Construção de instrumento para identificação da carga de trabalho da equipe de enfermagem em unidades pediátricas [dissertação]. São Paulo: Escola de Enfermagem, Universidade de São Paulo; 2006.

\section{RESUMO}

A pesquisa teve por objetivo construir um instrumento para identificação da carga de trabalho da equipe de enfermagem em unidades pediátricas e realizar a validação aparente do instrumento construído. $O$ instrumento para identificação da carga de trabalho da equipe, na área de pediatria, foi elaborado a partir da eleição de um sistema padronizado de linguagem, com a finalidade de comunicar um significado comum aos diversos locais de atendimento. Dentre as classificações analisadas, optou-se por utilizar a Classificação das Intervenções de Enfermagem (NIC). Para compor o instrumento foram selecionadas, na NIC, as intervenções e as atividades consideradas relevantes para a assistência de enfermagem pediátrica. Essas intervenções e atividades foram distribuídas em domínios classes, conservando-se a estrutura taxonômica da NIC. A seguir foram descritas em diferentes níveis, de acordo com a natureza das ações e o tempo estimado para a sua realização. Para a validação aparente do instrumento foram convidadas enfermeiras com conhecimento em cada um dos temas envolvidos na sua construção: Assistência de Enfermagem Pediátrica; Sistema de Classificação de Pacientes e Classificação das Intervenções de Enfermagem. A análise dessas enfermeiras considerou que as intervenções e atividades selecionadas, para a composição do instrumento, são relevantes e representam a prática da assistência de enfermagem pediátrica. Com a identificação das intervenções e atividades que representam a carga de trabalho da equipe de enfermagem, vislumbra-se o desenvolvimento de novas pesquisas, no sentido de realizar testes de confiabilidade e validade do instrumento, para verificar sua aplicabilidade na prática assistencial e gerencial, bem como correlacionar cada uma dessas intervenções e atividades com o tempo despendido para a sua realização, de forma a constituir um instrumento que determine a carga de trabalho da equipe de enfermagem das unidades pediátricas.

Palavras-chave: administração de recursos humanos; dimensionamento de recursos humanos; carga de trabalho; enfermagem pediátrica. 
Santos NC. Building an instrument for the identification of nursing staff workload in pediatric units [dissertation]. São Paulo: Escola de Enfermagem, Universidade de São Paulo; 2006.

\begin{abstract}
This research aimed to build an instrument for the identification of nursing staff workload in pediatric units and make the apparent validation of the instrument built. The instrument for the identification of staff workload, in the pediatric area, was created by the election of a standardized system of language, for the purpose of communicating a meaning in common to the several places of attendance. Among the classification analyzed, it was chosen to use the Nursing Intervention Classification (NIC). For composing the instrument it was selected at the NIC the interventions and activities considered relevant for the pediatric nursing care. These interventions and activities were distributed in group masteries, keeping the taxonomic structure of NIC. Next, they were described in different levels, according to the nature of actions and the estimated time for its accomplishment. For the apparent validation of the instrument, nurses experienced in each one of the following themes involved in the building were invited: Pediatric Nursing Care, Patient Classification System and Nursing Intervention Classification. The nurses' analyses considered that the selected interventions and activities, for composing the instrument, are relevant and represent the practice of pediatric nursing care. Identifying the interventions and activities that represent nursing staff workload made it possible to predict the development of new researches in the sense of applying reliability and validity tests for the instrument, verifying its applicability in the practitioner and management practice, as well as matching each one of these interventions and activities to the time spent for its accomplishment, in a way to constitute an instrument that determine nursing staff workload in the pediatric units.
\end{abstract}

Key words: human resources management, human resources dimensioning, workload, pediatric nursing. 


\section{Introdução}

O planejamento e a avaliação qualitativa e quantitativa de pessoal de enfermagem constituem-se em importantes atividades gerenciais do enfermeiro, necessitando de métodos e instrumentos adequados para sua realização.

No Brasil, o método de dimensionamento, proposto por Gaidzinski ${ }^{(1)}$, )tem subsidiado a realização dessas atividades, instrumentalizando os enfermeiros para a elaboração de propostas relacionadas à previsão e adequação do quadro de pessoal de enfermagem das instituições de saúde.

Uma das principais etapas desse método refere-se à identificação da carga de trabalho da unidade de assistência de enfermagem, compreendida como o produto da quantidade média diária de pacientes/clientes assistidos, segundo o grau de dependência da equipe de enfermagem, pelo tempo médio de enfermagem utilizado, por cliente, de acordo com o grau de dependência da equipe de enfermagem ${ }^{(2)}$.

Dessa forma, verifica-se que a determinação da carga de trabalho das unidades de assistência de enfermagem depende do conhecimento do grau de dependência dos pacientes em relação à equipe de enfermagem. A identificação dessa variável pressupõe a adoção e utilização de um Sistema de Classificação de Pacientes (SCP).

O conceito de SCP, inicialmente denominado Cuidado Progressivo ao Paciente (CPP), surgiu da necessidade das organizações de saúde em racionalizar o trabalho e, conseqüentemente, os recursos humanos e materiais ${ }^{(3)}$. 
De acordo com Johnson ${ }^{(4)}$, o SCP tem sua origem nos modelos de "reengenharização" industrial, utilizados para mensurar a produtividade. Em um processo produtivo são estabelecidos, de modo distinto, as atividades e o tempo correspondente à sua realização. A interpretação desses dados é útil para dimensionar o quadro de pessoal, em função das atividades a serem desenvolvidas.

Giovanetti $^{(5)}$ conceituou o SCP como a identificação e classificação de pacientes em grupos de cuidados ou categorias, e a quantificação dessas categorias como uma medida dos esforços de enfermagem requeridos.

Para Gaidzinski ${ }^{(6)}$, o SCP pode ser entendido como uma forma de determinar o grau de dependência de um paciente em relação à equipe de enfermagem, objetivando estabelecer o tempo despendido no cuidado direto e indireto, bem como o qualitativo de pessoal, para atender às necessidades bio-psico-sócio-espirituais do paciente.

O objetivo primordial de um SCP consiste em combinar necessidades do paciente com recursos disponíveis de enfermagem. A partir disso, tornase mais fácil para o gerente de enfermagem realizar uma estimativa do volume de trabalho do pessoal de enfermagem em cada unidade, possibilitando projeções mais racionais e efetivas do quadro de pessoal necessário para o atendimento das necessidades individualizadas dos pacientes $^{(7)}$.

Alward $^{(8)}$ considera que o SCP, além de possibilitar ao enfermeiro avaliar e adequar o volume de trabalho requerido com o pessoal de enfermagem disponível, auxilia a justificar a necessidade de pessoal 
adicional, quando ocorre aumento do volume de trabalho na unidade.

Nessa mesma direção, Wrona-Sexton ${ }^{(9)}$ refere que quando não se dispõe de instrumentos de mensuração da complexidade assistencial dos pacientes, torna-se difícil a alegação de que os pacientes estão se tornando mais graves, demandando, conseqüentemente, mais horas de cuidado e mais recursos de enfermagem.

De acordo com Fugulin, Gaidzinski e Kurcgant ${ }^{(10)}$, a introdução do conceito de SCP na prática gerencial do enfermeiro contribuiu para o aperfeiçoamento dos modelos utilizados para a determinação da carga de trabalho da equipe de enfermagem, uma vez que evidencia a variação do tempo médio de trabalho de enfermagem dedicado aos pacientes classificados nas diferentes categorias de cuidado, possibilitando, também, a adequação dos métodos utilizados na determinação dos custos da assistência prestada.

Os precursores do estudo de classificação de pacientes foram os pesquisadores do John Hopkins University and Hospital, nos Estados Unidos, que em 1960, desenvolveram e introduziram um SCP fundamentado no grau de necessidades do paciente em relação à assistência de enfermagem $^{(11)}$. Os pacientes foram, inicialmente, classificados em três grupos: autocuidado, cuidado parcial ou intermediário e cuidado intensivo ou total. A média de horas de assistência de enfermagem foi determinada para cada classificação. Os pesquisadores concluíram o estudo afirmando que a utilização desse sistema possibilitava a estimativa diária de necessidades dos pacientes em relação à assistência de enfermagem. 
Nessa perspectiva, estudos sobre dimensionamento de pessoal de enfermagem, utilizando o SCP como fundamentação para a determinação das horas de assistência, foram desenvolvidos por vários autores.

Barhan e Schneider ${ }^{(12)}$, em 1980, apresentaram, nos Estados Unidos, um instrumento denominado Matrix, que contém em uma única matriz o sistema de classificação de pacientes, o tempo despendido em cada área de cuidado, de acordo com a categoria profissional e o turno de trabalho, bem como as horas totais de assistência encontradas em cada um dos níveis de cuidados estabelecidos (nível I, II, III e IV).

A partir da divulgação deste estudo, em 1981, a Joint Comission of Accreditation of Hospitals (JCAH), comissão que avalia os padrões de assistência dos hospitais naquele país, recomendou aos serviços de enfermagem, definir, implementar e manter um sistema para determinar as necessidades de cuidados de enfermagem do paciente, do tipo Matrix ${ }^{(8,13)}$. Dessa forma, na realidade americana, diversas propostas de SCP foram desenvolvidas, cada uma delas indicando valores diferentes para as horas de assistência de enfermagem, de acordo com as categorias de cuidado estabelecidas $^{(14)}$.

A Organização Mundial de Saúde (OMS) e a Organização Panamericana de Saúde (OPAS), preocupadas em implementar e garantir a qualidade nos hospitais latino-americanos, propuseram a utilização de programas de acreditação mencionando, em seu manual, a categorização como um método criterioso a ser utilizado para a classificação de serviços, de acordo com critérios como risco de atenção ${ }^{(15)}$. 
No Brasil, o SCP, foi introduzido por Ribeiro ${ }^{(16)}$, em 1972, quando, em sua Tese de Doutorado, indicou o SCP como um método capaz de instrumentalizar o dimensionamento de recursos humanos em enfermagem de forma a assegurar uma distribuição mais eqüitativa da assistência, aumento da produtividade e eficiência hospitalar.

Giovannetti $^{(5)}$ considera dois tipos de instrumentos para a classificação de pacientes: Sistema Protótipo ou Avaliação Protótipo e Sistema Avaliação de Indicadores Críticos.

O Sistema Protótipo, considerado mais subjetivo, é um instrumento que descreve o perfil de cada tipo de cuidado ou grau de dependência de enfermagem, baseado no CPP, estabelecendo de três a quatro categorias na classificação. Assim, o paciente é classificado em uma das categorias propostas, de acordo com a correspondência entre o perfil apresentado e as definições das categorias de cuidados utilizadas para a sua classificação $(5,13,17-19)$

O Sistema de Avaliação de Indicadores Críticos, mais objetivo, classifica o paciente por meio da atribuição de pontos que são estabelecidos de acordo com a complexidade do cuidado e da dependência que o paciente apresenta em relação à equipe de enfermagem diante de indicadores críticos, tais como: higiene, nutrição, eliminações e movimentação, entre outros. A categoria, na classificação, é determinada pelo total de pontos atribuídos a cada paciente ${ }^{5,13,17-19}$.

Alcalá et al. ${ }^{(20)}$ desenvolveram, junto à Superintendência Médica Hospitalar de Urgência do município de São Paulo, um instrumento de 
classificação de pacientes, do tipo protótipo, estabelecendo o perfil de cada tipo de cuidado a partir do conceito do Cuidado Progressivo ao Paciente, classificando os pacientes internados em quatro níveis de atenção ou tipos de cuidado: intensivo, semi-intensivo, intermediário e mínimo ou autocuidado.

Para calcular as horas de assistência, em cada tipo de cuidado, Alcalá et al. ${ }^{(20)}$ pesquisaram diversas instituições particulares e governamentais, considerando o tipo de clientela, a intensidade de atenção aos pacientes, de acordo com sua faixa etária, e assim obtiveram os valores padrões de horas de enfermagem. Esses pesquisadores encontraram uma diferença entre as horas de cuidado intermediário e mínimo de pacientes adultos e pediátricos, conforme indicado no Quadro 1:

QUADRO 1 - Horas médias de assistência de enfermagem, segundo a categoria de cuidado, indicadas por Alcalá et al.

\begin{tabular}{|c|c|c|}
\hline \multirow{2}{*}{ TIPO DE CUIDADO } & \multicolumn{2}{|c|}{ TIPO DE PACIENTE } \\
\cline { 2 - 3 } & ADULTO/HORA & PEDIATRIA/HORA \\
\hline INTENSIVO & 18,0 & 18,0 \\
\hline SEMI-INTENSIVO & 10,0 & 10,0 \\
\hline INTERMEDIÁRIO & 4,5 & 5,5 \\
\hline MÍNIMO & 2,5 & 4,5 \\
\hline
\end{tabular}

Fonte: Alcalá et al., 1982

O mesmo método foi empregado por Alves et al. ${ }^{(21)}$, quando estabeleceram horas médias de assistência de enfermagem para as 
diferentes categorias de cuidado, indicando parâmetros diferenciados para o paciente pediátrico, conforme demonstra o Quadro 2:

QUADRO 2 - Horas médias de assistência de enfermagem, segundo a categoria de cuidado, estabelecidas por Alves et al.

\begin{tabular}{|l|c|c|c|c|}
\hline \multirow{2}{*}{$\begin{array}{c}\text { Categorias de } \\
\text { cuidado }\end{array}$} & \multicolumn{4}{|c|}{ Horas Médias de enfermagem nas unidades de internação } \\
\cline { 2 - 5 } & Intensivo & Intermediário & Auto-cuidado & Pediátrico \\
\hline Intensivo & 11 & - & - & - \\
\hline Semi-intensivo & 7 & 10 & - & - \\
\hline Cuidado especial & - & - & 4,5 & 5 \\
\hline Intermediário & - & 4,5 & 3 & 4,5 \\
\hline Mínimo & - & 2,5 & 2,5 & 3 \\
\hline
\end{tabular}

Fonte: Alves et al.,1988

Fugulin et al. ${ }^{(22)}$ desenvolveram um instrumento do tipo protótipo, descrevendo o perfil assistencial dos pacientes internados na Unidade de Clínica Médica do Hospital Universitário da Universidade de São Paulo, considerando nove áreas de cuidado (estado mental, oxigenação, sinais vitais, motilidade, deambulação, alimentação, cuidado corporal, eliminação e terapêutica). Os autores definiram cinco categorias de classificação, de acordo com a dependência dos pacientes em relação à assistência de enfermagem: cuidados intensivos; cuidados semi-intensivos; cuidados alta dependência, cuidados intermediários e cuidados mínimos.

Perroca $^{(23)}$ construiu e validou um instrumento de classificação de pacientes, do tipo sistema de avaliação de indicadores críticos, baseado nas necessidades individualizadas de cuidado de enfermagem, considerando 13 indicadores críticos: estado mental e nível de consciência; oxigenação; sinais vitais; nutrição e hidratação; motilidade; locomoção; cuidado corporal; 
eliminações; terapêutica; educação à saúde; comportamento; comunicação e integridade cutâneo-mucosa.

Cada indicador possui gradação de um a cinco, conforme a intensidade crescente da complexidade assistencial. Assim, o paciente é avaliado em relação a todos os indicadores, na opção que melhor retrate sua situação, sendo classificado na categoria de cuidado correspondente à soma dos valores parciais obtidos.

Essa autora ${ }^{(23)}$ estabeleceu quatro categorias de cuidado, de acordo com as definições propostas por Fugulin et al. ${ }^{(22)}$, adaptando o conceito da categoria de cuidado semi-intensivo, uma vez que seu instrumento não adota a categoria de cuidado alta dependência de enfermagem. $O$ instrumento proposto compreende, dessa maneira, as categorias de cuidado intensivo, semi-intensivo, intermediário e mínimo.

A partir desses estudos, outros SCP foram desenvolvidos por diferentes autores ${ }^{(24-31)}$, em diferentes realidades, sem indicarem, no entanto, as horas de enfermagem correspondentes às diferentes categorias de cuidado, a exemplo do que ocorre com os instrumentos de Fugulin et al. ${ }^{(22)}$ e de Perroca ${ }^{(23)}$.

Diante da inexistência de parâmetros oficiais para a operacionalização do processo de dimensionar pessoal de enfermagem, o Conselho Federal de Enfermagem (COFEN) estabeleceu por meio da Resolução $n^{\circ}$ 189/96 ${ }^{(32)}$, parâmetros mínimos para o dimensionamento de pessoal de enfermagem nas instituições hospitalares brasileiras, apontando a distribuição percentual dos profissionais de enfermagem e as horas médias de assistência de 
enfermagem, para cada tipo de cuidado, com base no SCP desenvolvido por Fugulin et al. ${ }^{(22)}$, deixando de incluir, no entanto, a categoria de cuidados de alta dependência de enfermagem, conforme demonstra o Quadro 3:

QUADRO 3 - Horas médias de assistência e distribuição percentual dos profissionais de enfermagem, segundo categoria de cuidado, estabelecidas pela Resolução COFEN n 189/96.

\begin{tabular}{|l|c|c|c|}
\hline \multicolumn{1}{|c|}{$\begin{array}{c}\text { Categoria de Cuidados } \\
\text { de enfermagem }\end{array}$} & \multicolumn{3}{|c|}{ Resolução 189/96 } \\
\cline { 2 - 4 } & $\begin{array}{c}\text { Horas de enfl } \\
\text { leito/ 24 hs }\end{array}$ & \% Enfermeiros & \% Tec.l Aux. Enf. \\
\hline $\begin{array}{l}\text { Assistência Mínima ou Auto- } \\
\text { cuidado }\end{array}$ & 3,0 & 27 & 73 \\
\hline Assistência Intermediária & 4,9 & 27 & 73 \\
\hline Assistência Semi-intensiva & 8,5 & 40 & 60 \\
\hline Assistência intensiva & 15,4 & 55,6 & 44,4 \\
\hline
\end{tabular}

Em 2004, o COFEN, revogando a Resolução anterior, indicou, por meio da Resolução $n^{\circ} 293 / 04^{(33)}$, novos parâmetros para dimensionar o quantitativo mínimo dos diferentes níveis de formação dos profissionais de enfermagem para a cobertura assistencial nas instituições de saúde. Os novos parâmetros foram estabelecidos através de sugestões de enfermeiros gerentes de unidades assistenciais de várias regiões do Brasil, sobre o quadro ideal de pessoal de enfermagem para assistir a um número específico de pacientes de cuidado mínimo, intermediário, semi-intensivo e intensivo. O Quadro 4, apresentado a seguir, evidencia os parâmetros indicados por essa Resolução ${ }^{(33)}$. 
QUADRO 4 - Horas médias de assistência e distribuição percentual dos profissionais de enfermagem, segundo a categoria de cuidado, estabelecidas pela Resolução COFEN n 293/04.

\begin{tabular}{|l|c|c|c|}
\hline \multirow{2}{*}{$\begin{array}{c}\text { Categoria de Cuidados } \\
\text { de enfermagem }\end{array}$} & \multicolumn{3}{|c|}{ Resolução 293/04 } \\
\cline { 2 - 4 } & $\begin{array}{c}\text { Horas de enf /leitol } \\
\mathbf{2 4} \mathbf{~ h s}\end{array}$ & \% Enfermeiros & \% Tec. / Aux. Enf \\
\hline $\begin{array}{l}\text { Assistência Mínima ou Auto- } \\
\text { cuidado }\end{array}$ & 3,8 & 33 a 37 & 67 a 63 \\
\hline Assistência Intermediária & 5,6 & 33 a 37 & 67 a 63 \\
\hline Assistência Semi-intensiva & 9,4 & 42 a 46 & 58 a 54 \\
\hline Assistência intensiva & 17,9 & 52 a 56 & 48 a 44 \\
\hline
\end{tabular}

Em sua tese de doutorado, Fugulin ${ }^{(3)}$ utilizou o SCP desenvolvido na Unidade de Clínica Médica para classificar os pacientes das Unidades de Internação do HU-USP. Para homogeneizar sua aplicação, atribuiu pesos a cada nível de dependência em relação às áreas de cuidado, transformando este instrumento num sistema misto, que além de descrever o perfil apresentado pelo paciente e definir a categoria de cuidados utilizados para a sua classificação, estabelece uma pontuação de acordo com a complexidade do cuidado e da dependência que o paciente apresenta em relação à equipe de enfermagem.

A autora ${ }^{(3)}$ concluiu que a classificação diária dos pacientes forneceu informações acerca do perfil assistencial e da carga de trabalho existente em cada Unidade de Internação. Considerou, ainda, que o conhecimento do perfil assistencial dos pacientes pode subsidiar o planejamento e a implementação de programas assistenciais que melhor atendam às necessidades da clientela, auxiliando na distribuição diária e na capacitação 
dos recursos humanos para o atendimento de cada grupo de pacientes, em cada Unidade.

Entretanto, verificou, também, que este instrumento não se aplica para as Unidades de Berçário e Pediatria, bem como não identifica os diferentes níveis de gravidade e dependência de enfermagem dos pacientes das Unidades de Terapia Intensiva (UTI). Assim, sugeriu a construção de instrumentos específicos para as áreas de neonatologia e pediatria e, no contexto das unidades de terapia intensiva, que sejam identificados, testados e validados instrumentos que retratem de forma mais fidedigna a realidade e as características específicas dos pacientes críticos ${ }^{(3)}$.

Nessa direção, verifica-se, no cenário internacional, a proposição de instrumentos que procuram quantificar a carga de trabalho de enfermagem e avaliar a adequação qualitativa e quantitativa de pessoal para o atendimento das necessidades assistenciais dos pacientes de Unidades de Terapia Intensiva (UTI), tais como: o $\mathrm{OMEGA}^{(34)}$, proposto pela Commission d'Evaluation de la Société de Reanimation da Langue Française, na França; o Time Orientes Score Sysrem ${ }^{(35)}$ (TOSS), descrito como resultado de um estudo do Italian Multicenter Group of ICU Research, na Itália; O Nine Equivalents of Nursing Manpower Use Score ${ }^{(36)}$ (NEWS), desenvolvido na Holanda, por Reis Miranda et al..

Dentre esses instrumentos o Therapeutic Intervention Scoring System $^{(37)}$ (TISS) e o Nursing Activies Score ${ }^{(38)}$ (NAS), têm sido indicados como instrumentos sensíveis e promissores para dimensionar a carga de trabalho da equipe de enfermagem. 
O Therapeutic Intervention Scoring System (TISS), desenvolvido por Cullen e colaboradores ${ }^{(37)}$, concebido, originalmente, como um índice indireto de gravidade, tem sido utilizado como ferramenta para a estimativa da carga de trabalho em UTI. O TISS tem por princípio que quanto mais grave o estado do paciente, maior o número de intervenções terapêuticas necessárias para o seu tratamento e, conseqüentemente, maior o tempo de enfermagem para o seu atendimento.

Em sua primeira versão o TISS era composto por 57 intervenções terapêuticas, tendo sido reformulado, em 1983 e em 1996. A versão atual, TISS-28, desenvolvida por Miranda et al. ${ }^{(39)}$, reduziu para 28 o número de intervenções analisadas. $\mathrm{O}$ escore final desse novo instrumento varia de 0 a 76 pontos, permitindo a determinação da carga de trabalho da equipe de enfermagem, uma vez que cada ponto do TISS-28 consome 10,6 minutos do tempo de um enfermeiro na assistência ao paciente.

Apesar das importantes contribuições do TISS, verificou-se que este instrumento não contempla o conjunto de atividades desenvolvidas pela enfermagem.

No intuito de ajustar o TISS-28, de modo a avaliar mais fielmente a carga de trabalho da equipe de enfermagem em UTI, Miranda et al. ${ }^{(39)}$ reestruturam este instrumento e apesar de manterem o mesmo número de categorias do TISS-28, suprimiram ou aglutinaram alguns itens, bem como acrescentaram atividades de enfermagem não contempladas na versão anterior, como por exemplo: procedimentos de higiene, mobilização e posicionamento do paciente, suporte e cuidados aos familiares, atividades 
administrativas e gerenciais.

A metodologia utilizada para validação dos itens e determinação da pontuação dos seus valores, foi a "Work-Sampling" ou "Amostragem do trabalho". A amostragem do trabalho é um método de medida de trabalho que se baseia em observações casuais, porém sistemáticas, de atividades de um trabalhador, com o objetivo de mensurar como o tempo de um dia de trabalho é gasto(40).

Após extensa análise estatística, que resultou na atribuição de pesos para os vários itens, o novo instrumento foi concluído, passando a ser denominado Nursing Activies Score (NAS). O escore final, obtido com a sua pontuação, representa a porcentagem do tempo gasto por um enfermeiro, em um turno de trabalho, variando de 0 a $100 \%$ ou mais ${ }^{(38)}$.

O NAS foi traduzido e validado para língua portuguesa, por Queijo ${ }^{(41)}$, o que possibilita sua utilização no contexto nacional.

Aplicado em uma unidade de terapia intensiva do município de São Paulo, esse instrumento mostrou-se útil para a avaliação da carga de trabalho da equipe de enfermagem sendo apontadas, no entanto, dificuldades decorrentes da ausência de maior detalhamento operacional ${ }^{(42)}$.

No que se refere às áreas de pediatria e neonatologia, embora se verifique o desenvolvimento de instrumentos que propõem a avaliação da gravidade dos pacientes, tais como: o Physiological Stability Index ${ }^{(43)}(\mathrm{PSI})$, o Pediatric RisK of Mortality ${ }^{(4)}$ (PRISM), e o Neonatal Therapeutic Intervention Scoring ${ }^{(45)}$ (NTISS), constata-se a inexistência de instrumentos que auxiliem na determinação da carga de trabalho da equipe de 
enfermagem, uma vez que nenhum desses instrumentos considera a relação entre os cuidados de enfermagem e o tempo despendido para sua realização.

O COFEN, ao referendar o SCP de Fugulin et al. ${ }^{(22)}$, que define as categorias de cuidado com base nas características e no perfil de pacientes adultos, também deixou de contemplar as necessidades específicas dos pacientes pediátricos. No entanto, recomendou a utilização desse instrumento para a classificação dessa clientela, ao estabelecer no artigo $4^{\circ}$ da Resolução $293 / 04^{(33)}$.

$\S 7^{\circ}$ - Para berçário e unidade de internação em pediatria, caso não tenha acompanhante, a criança menor de seis anos e o recém-nascido (RN) devem ser classificados como necessidades de cuidados intermediários.

Essa recomendação do COFEN suscita muitas dúvidas e questionamentos, pois sugere que o recém nascido e a criança menor de seis anos, que permanecem com acompanhante, devem ser classificadas na categoria de cuidados mínimos, que se refere à "pacientes estáveis sob o ponto de vista clínico e de enfermagem que requeiram avaliações médicas e de enfermagem, mas fisicamente auto-suficientes quanto ao atendimento das necessidades humanas básicas". Assim, pressupõe que o atendimento das necessidades básicas da criança e do recém nascido estavam sendo atendidas pelo acompanhante, deixando de observar que as atribuições e responsabilidade da equipe de enfermagem não podem ser repassadas para o acompanhante que, apesar de poder participar e realizar atividades como higiene e alimentação, não podem absorver a carga de trabalho da equipe 
de enfermagem.

A presença do acompanhante pediátrico, garantida pelo Estatuto da Criança e do Adolescente, tem a finalidade de dar suporte emocional à criança, beneficiando a sua recuperação. No entanto, apesar dos inúmeros benefícios, a presença do acompanhante, muitas vezes, incorre em um aumento da carga de trabalho da equipe de enfermagem, por demandar uma disponibilidade maior de tempo dos profissionais, principalmente no que diz respeito às necessidades de orientação, supervisão e treinamento. Outras demandas surgem, ainda, quando o acompanhante não aceita orientações, não permite ou dificulta a realização de procedimentos, ou apresenta alterações comportamentais que exigem vigilância contínua da equipe de enfermagem.

A inexistência de um referencial próprio, que possibilite a classificação dos pacientes pediátricos e neonatais, de acordo com as suas características específicas, faz com que as enfermeiras classifiquem esses pacientes de maneira equivocada, utilizando parâmetros que não traduzem as reais necessidades assistenciais dessa clientela e, conseqüentemente, provocando distorções na previsão do quantitativo de pessoal de enfermagem.

Diante desse cenário, considera-se que a construção de um instrumento para mensurar a carga de trabalho da equipe de enfermagem em unidades pediátricas, que contemple as características específicas dessa clientela, possa constituir-se em uma ferramenta gerencial capaz de subsidiar, de forma consistente, a operacionalização do processo de 
dimensionar pessoal de enfermagem nessa área, contribuindo, conseqüentemente, para o enfrentamento da problemática que envolve o planejamento e a provisão de recursos humanos de enfermagem em pediatria.

Assim, este estudo tem a finalidade de propor um instrumento que represente as ações desenvolvidas pela equipe de enfermagem junto ao paciente pediátrico, nos diversos níveis de complexidade assistencial, e que possibilite a identificação da carga de trabalho dos profissionais que atuam nessa área. Pretende-se, futuramente, desenvolver uma nova investigação que correlacione essas ações com o tempo despendido para a sua realização, de forma a compor um instrumento de mensuração da carga de trabalho da equipe de enfermagem em unidades pediátricas. 


\section{Objetivos}

- Construir um instrumento para identificação da carga de trabalho da equipe de enfermagem em unidades pediátricas.

- Realizar a validação aparente do instrumento construído 


\section{Método}

\subsection{Tipo de Estudo}

Trata-se de uma pesquisa metodológica, que de acordo com Polit e Hungler ${ }^{(46)}$, "refere-se às investigações de métodos de obtenção, organização e análise de dados, tratando da elaboração, validação e avaliação dos instrumentos e técnicas de pesquisa".

\subsection{Trajetória Metodológica}

O estudo desenvolveu-se em duas etapas: construção do instrumento para identificação da carga de trabalho da equipe de enfermagem em unidades pediátricas e validação aparente do instrumento construído.

\subsubsection{Construção do Instrumento}

O instrumento para identificação da carga de trabalho da equipe de enfermagem, na área pediátrica, foi elaborado a partir da eleição de um sistema padronizado de linguagem, próprio da enfermagem, com a finalidade de comunicar um significado comum aos diversos locais de atendimento, bem como auxiliar o aperfeiçoamento da prática assistencial e gerencial, por meio do desenvolvimento de pesquisas que permitam a comparação e a avaliação dos cuidados de enfermagem prestados em diferentes cenários ${ }^{(47)}$. 
A padronização da linguagem pode ser obtida através da utilização de classificações, reconhecidas internacionalmente.

As classificações são ferramentas utilizadas para melhorar a descrição de fenômenos que estabelecem, por meio de uma nomenclatura própria, significados comuns aos diversos termos utilizados na prática profissional.

De acordo com McCloskey e Bulecheck ${ }^{(47)}$, as classificações contribuem para o avanço da base de conhecimento de uma área por meio da organização desse conhecimento e da descoberta dos princípios orientadores daquilo que é conhecido.

Dentre as padronizações mais utilizadas, apresenta-se a taxonomia II ${ }^{(48)}$ da North American Nursing Diagnosis Association (NANDA), que consiste na utilização de uma nomenclatura para descrever as situações ou condições que são diagnosticadas e tratadas na prática de enfermagem, ou seja, uma taxonomia multiaxial, que permite a individualização do diagnóstico de enfermagem, retratando as respostas da clientela aos processos de saúde ou aos processos vitais. A taxonomia II $^{(48)}$, versão atualizada e revisada da taxonomia I, compreende a organização dos diagnósticos de enfermagem dentro de domínios e classes, constituindo 13 domínios, 46 classes e 155 diagnósticos. Cada domínio contém sua conceituação e denominação, e cada classe, pertencente a esses domínios, possui os conceitos diagnósticos e os diagnósticos aprovados pela NANDA. A taxonomia da NANDA foi o primeiro sistema de linguagem reconhecido pela American Nurses Association (ANA). 
A Classificação Internacional para a Prática de Enfermagem ${ }^{\circledR(49)}$ conhecida como $\mathrm{CIPE}^{\circledR}$, uma iniciativa do Conselho Internacional de Enfermeiros, é uma nomenclatura de fenômenos, ações e resultados de enfermagem, que fornece uma terminologia para a prática profissional e serve como uma estrutura unificada contendo vocabulários e classificações de enfermagem que podem ser utilizadas para mapeamento e comparação dos dados de enfermagem.

Desenvolvida a partir da prática em saúde comunitária, a classificação de Omaha tem como finalidade documentar os cuidados e gerenciar o sistema de cuidados à saúde e os dados dessa prática. Constitui-se de diagnósticos, intervenções de enfermagem e escala de resultados ${ }^{(50)}$.

A Classificação das Intervenções de Enfermagem ${ }^{(47)}$ (NIC), desenvolvida por um grupo de enfermeiras pesquisadoras do Centro para Classificação em Enfermagem, da Escola de Enfermagem de lowa, Estados Unidos, nomeia e descreve intervenções que os profissionais de enfermagem executam na prática clínica, em resposta a um diagnóstico de enfermagem estabelecido.

A Classificação das Intervenções de Enfermagem tem ligações com os diagnósticos da NANDA ${ }^{(48)}$, com a classificação de problemas de Omaha $^{(50)}$ e com a Classificação dos Resultados de Enfermagem ${ }^{(51)}$ (NOC). Todas essas classificações, reconhecidas pela ANA, são continuamente revisadas e atualizadas.

Segundo McCloskey e Bulecheck ${ }^{(47)}$, a NIC é um sistema útil para a documentação clínica; para a comunicação de diferentes cuidados entre 
unidades de tratamento; para a integração de dados em sistemas de informação; para a eficácia das pesquisas; para a medida da produtividade; para a avaliação de competências e para o planejamento curricular.

A Classificação Internacional de Resultados de Enfermagem ${ }^{(51)}$ (NOC), desenvolvida, também, por uma grande equipe de alunos e pesquisadores da Escola de Enfermagem da Universidade de lowa, contêm resultados para pacientes, cuidador familiar, família e comunidade e provê elementos para a avaliação e documentação das respostas aos cuidados de enfermagem.

McCloskey e Bulecheck ${ }^{(47)}$ referem que a partir da identificação das intervenções mais utilizadas junto a determinados grupos de clientes é possível estabelecer os recursos necessários para sua execução, o nível de complexidade do cuidado, a categoria do profissional envolvido e o tempo despendido para sua realização.

Diante dessas considerações e, observando a tendência mundial das instituições de saúde em utilizar a associação da $\operatorname{NANDA}^{(48)}, \mathrm{NIC}^{(47)}$ e $\mathrm{NOC}^{(51)}$ para a avaliação de processos e resultados dos cuidados de enfermagem, optou-se por construir o instrumento com base na Classificação das Intervenções de Enfermagem ${ }^{(47)}$.

O termo intervenção de enfermagem é definido como qualquer tratamento, baseado no julgamento e no conhecimento clínico, que a enfermeira desempenha para melhorar os resultados do paciente/ cliente ${ }^{(46)}$.

A estrutura taxonômica da NIC esta constituída por três níveis sendo o primeiro, representado por sete domínios: Fisiológico básico, Fisiológico 
complexo, Comportamento, Segurança, Família, Sistema de Saúde e Comunidade. O segundo nível é representado por 30 classes, organizadas dentro dos domínios e o terceiro nível é constituído por 486 intervenções de enfermagem, agrupadas de acordo com as classes e os domínios ${ }^{(47)}$.

A taxonomia da NIC foi codificada com a finalidade de aumentar sua articulação com os outros sistemas de códigos, facilitar o uso de computadores e a manipulação de $\operatorname{dados}^{(47)}$.

Os códigos dos sete domínios vão de 1 a 7 e os códigos das 30 classes vão de A a Z; a ,b, c, d. Cada intervenção possui um único número com quatro dígitos e apresenta uma lista de dez a 30 atividades, que estão codificadas pelo uso decimal de dois dígitos. As atividades se referem a comportamentos e ações específicos, realizados para implementar uma intervenção ${ }^{(47)}$.

As intervenções de enfermagem da NIC são constituídas pelo título, pela definição e por uma lista de atividades, que descrevem as ações dos profissionais ao executar a intervenção de enfermagem ${ }^{(47)}$.

O título e a definição, por constituírem uma linguagem padronizada, não podem ser mudados, a não ser por um processo formal de revisão. As atividades podem ser modificadas, de acordo com a necessidade particular do paciente, proporcionando a individualização do cuidado ${ }^{(47)}$.

A construção deste instrumento teve início com a realização de várias leituras da NIC, visando a compreensão da sua complexa estrutura, das definições de cada domínio, classe e intervenção e a identificação das atividades relacionadas em cada intervenção. 
Em seguida, as intervenções e atividades foram selecionadas, elegendo-se, para compor o instrumento, aquelas consideradas relevantes para a prática de enfermagem pediátrica.

As intervenções e atividades selecionadas foram mantidas dentro dos domínios e classes, de acordo com o agrupamento hierárquico estabelecido na $\mathrm{NIC}^{(47)}$.

Durante essa fase de seleção, constatou-se que algumas intervenções estavam indicadas em mais de uma classe, tendo-se optado por mantê-las na que melhor representasse a sua relevância na assistência de enfermagem pediátrica. A exemplo disso, a intervenção "Cuidados com Ostomia", que esta indicada nas classes B (Controle das Eliminações) e L (Controle de Pele/lesões), foi mantida na Classe L, embora sua numeração indicasse a localização principal na Classe B, por julgar-se que apresentava maior significado nos aspectos assistenciais daquela classe.

Posteriormente, as intervenções e atividades foram descritas em diferentes itens, de forma a retratar níveis crescentes, de acordo o tempo estimado para sua realização, com base na experiência profissional da pesquisadora.

Como a $\mathrm{NIC}^{(47)}$ é um sistema padronizado de linguagem reconhecido internacionalmente, preservou-se, na construção do instrumento, as nomenclaturas e definições por ela utilizadas, mantendo-se o uso de códigos somente para identificar os domínios e as classes.

Para identificar os diferentes níveis, de acordo com o tempo estimado para sua realização foram atribuídos, a cada nível, o código da classe 
correspondente, acrescido de uma indicação numérica, de maneira que fosse retratada a intensidade crescente do tempo despendido para a realização das atividades e intervenções indicadas.

\subsubsection{Validação aparente do instrumento}

Validade refere-se ao grau em que o instrumento mede aquilo que ele supõe estar medindo ${ }^{(52)}$.

Para Wood e Haber ${ }^{(53)}$, um instrumento é válido quando reflete verdadeiramente o conceito que deve medir.

A validade aparente ou de rosto é considerada um tipo intuitivo de validade em que se pede a colegas ou sujeitos da pesquisa, para lerem o instrumento e avaliarem se o conceito reflete o conceito que o pesquisador pretende medir. Esse procedimento pode ser útil no processo de desenvolvimento da ferramenta em relação à determinação da legibilidade e clareza do conteúdo(53).

Assim, a validação aparente tem o objetivo de verificar se o instrumento responde, numa visão geral, às questões da pesquisa que estão em estudo.

No caso da presente pesquisa, a validação aparente teve como finalidade verificar se as atividades e intervenções selecionadas e descritas, no instrumento proposto, representam a prática assistencial de enfermagem pediátrica e se possibilitam a identificação da carga de trabalho da equipe de enfermagem nessa área. 


\subsubsection{Participação das especialistas}

Para constituir o grupo de especialistas que participariam da validação aparente do instrumento considerou-se necessário garantir a presença de pelo menos uma enfermeira, com conhecimento em cada um dos temas envolvidos na sua construção: Assistência de Enfermagem Pediátrica; Sistema de Classificação de Pacientes e Classificação das Intervenções de Enfermagem.

Dessa forma, foram convidadas enfermeiras com experiência profissional mínima de cinco anos na prática ou no ensino de enfermagem pediátrica e no ensino ou desenvolvimento de pesquisas relacionadas às demais temáticas envolvidas na construção do instrumento.

Ao grupo de especialistas coube analisar o conteúdo do instrumento quanto à clareza e à pertinência das atividades em relação aos domínios e classes; clareza na descrição das intervenções e atividades; indicação de nível crescente de complexidade assistencial; relevância das intervenções e atividades para a prática da assistência de enfermagem pediátrica; inclusão ou exclusão das atividades nas classes; inclusão ou exclusão de classes nos domínios; exclusão de algum domínio, bem como indicar se o instrumento proposto representa a prática assistencial de enfermagem pediátrica.

Para tanto, foi construído um questionário com questões fechadas, reservando-se espaço para comentários e sugestões que julgassem pertinentes. 
Foram encaminhados, às especialistas carta-convite (Anexo A) esclarecendo sobre os objetivos da pesquisa; Termo de Consentimento Livre-esclarecido (Anexo B); apresentação e instruções para preenchimento do questionário (Anexo C) e questionário (Anexo D). Esses documentos foram enviados por e-mail, sendo acordado um prazo máximo de 20 dias para a sua devolução.

\subsection{Aspectos éticos da pesquisa}

O projeto de pesquisa, bem como o Termo de Consentimento Livreesclarecido (Anexo B), foram aprovados pelo Comitê de Ética em Pesquisa do HU-USP (Anexo E). 


\section{Resultados e discussão}

\subsection{Proposta inicial do instrumento}

A seleção das intervenções e atividades da NIC determinou a seleção das classes e domínios que constituíram o instrumento. Dessa forma, foram eleitos cinco domínios, representados por números, e 20 classes, representadas por letras, conforme demonstra o Quadro 5. 
QUADRO 5 - Distribuição dos Domínios e Classes selecionados para composição do instrumento.

\begin{tabular}{|c|c|}
\hline DomínIOS & Classes \\
\hline 1: FISIOLÓGICO BÁSICO & $\begin{array}{l}\text { A: CONTROLE DE ATIVIDADE E EXERCÍCIO } \\
\text { B: CONTROLE DE ELIMINAÇÕES } \\
\text { C: CONTROLE DE IMOBILIDADE } \\
\text { D: SUPORTE NUTRICIONAL } \\
\text { E: PROMOÇÃO DO CONFORTO FÍSICO } \\
\text { F: FACILITAÇÃO DO AUTOCUIDADO }\end{array}$ \\
\hline 2:FISIOLÓGICO COMPLEXO & $\begin{array}{l}\text { G: CONTROLE DE ELETRÓLITOS E ÁCIDO- } \\
\text { BÁSICO } \\
\text { H: CONTROLE DE DROGAS } \\
\text { I: CONTROLE NEUROLÓGICO } \\
\text { K: CONTROLE RESPIRATÓRIO } \\
\text { L: CONTROLE DE PELE/LESÕES } \\
\text { M: TERMORREGULAÇÃO } \\
\text { N: CONTROLE DA PERFUSÃO TISSULAR }\end{array}$ \\
\hline 3: COMPORTAMENTAL & $\begin{array}{l}\text { O: TERAPIA COMPORTAMENTAL } \\
\text { R: ASSISTÊNCIA AO ENFRENTAMENTO }\end{array}$ \\
\hline 4: SEGURANÇA & $\begin{array}{l}\text { U : CONTROLE DE CRISE } \\
\text { V: CONTROLE DE RISCOS }\end{array}$ \\
\hline 6: Sistema de SAÚdE & $\begin{array}{l}\text { Y: MEDIAÇÃO COM O SISTEMA DE SAÚDE } \\
\text { a: CONTROLE DO SISTEMA DE SAÚDE } \\
\text { b: CONTROLE DAS INFORMAÇÕES }\end{array}$ \\
\hline
\end{tabular}

As classes selecionadas foram incluídas no instrumento nos domínios correspondentes, todos contendo a definição da NIC. As atividades selecionadas em cada classe foram descritas em níveis crescentes, de acordo com o tempo estimado para a sua realização, variando de três a seis níveis.

Apresenta-se, a seguir, a proposta inicial do instrumento construído. 


\section{Instrumento de Classificação de Pacientes Pediátricos}

\section{Domínio 1: Fısıológıco BÁsıco}

\section{Cuidados que dão suporte ao funcionamento físico do organismo}

\section{Classe A : Controle dA ATIVIDADE e EXERcício}

Intervenções para organizar ou auxiliar a atividade física e a conservação e gasto de energia (NIC; 2004). Incluem atividades relacionadas à deambulação e à movimentação.

\begin{tabular}{|l|l|}
\hline A1 & Sem limitação de atividades físicas atividades realizadas de forma independente. \\
\hline A2 & $\begin{array}{l}\text { Deambulação/movimentação auxiliada pelo acompanhante ou repouso no leito } \\
\text { controlado pelo acompanhante, nas } 24 \text { horas, sob a supervisão da equipe de } \\
\text { enfermagem. }\end{array}$ \\
\hline A3 & $\begin{array}{l}\text { Repouso no leito controlado pela equipe de enfermagem; deambulação/movimentação } \\
\text { auxiliadas por um profissional de enfermagem. }\end{array}$ \\
\hline A4 & $\begin{array}{l}\text { Movimentação/deambulação realizada por } 2 \text { ou mais profissionais da equipe de } \\
\text { enfermagem. }\end{array}$ \\
\hline
\end{tabular}

\section{Classe B: CONTROLE dAS ELIMINAÇÕES}

Intervenções para estabelecer e manter padrões de eliminação intestinal e urinária normais e controlar complicações resultantes de padrões alterados (NIC; 2004). Incluem atividades relacionadas ao uso de vaso sanitário/comadre/urinol; troca de fraldas; higiene perineal; controles da freqüência, volume, consistência, cor, odor das eliminações intestinais e urinárias; cuidados com sondas e drenos; sondagem vesical intermitente ou de demora; cuidados com ostomia.

B1 Uso do vaso sanitário realizado de forma independente.

B2 Uso do vaso sanitário/comadre/urinol ou troca de fraldas e higiene perineal auxiliadas/realizadas pelo acompanhante, nas 24 horas, sob a supervisão da equipe de enfermagem.

B3 Uso do vaso sanitário/comadre/urinol ou troca de fraldas e higiene perineal auxiliadas/realizadas por um profissional da equipe de enfermagem, até 6 vezes em 24 horas, ou sondagem vesical de demora nas últimas 24 horas.

B4 Uso do vaso sanitário/comadre/urinol ou troca de fraldas e higiene perineal auxiliadas/realizadas por um profissional da equipe de enfermagem mais que 6 vezes em 24 horas.

B5 Controle de volume das eliminações através de urinol/peso de fraldas/saco coletor/sondas ou sondagem vesical intermitente, realizadas pela equipe de enfermagem. 


\section{Classe C: CONTROLE DA IMOBILIDADE}

Intervenções para controlar a restrição de movimentos corporais e as seqüelas (NIC; 2004). Incluem atividades como: mudança de decúbito, transporte, transferência de cama/cadeira/carrinho; cuidados com aparelho de gesso e trações; utilização de mecanismos para posicionamento.

C1 Mudança de decúbito, transporte, transferência do leito auxiliada/realizada pelo acompanhante, nas 24 horas, sob a supervisão da equipe de enfermagem.

C2 Mudança de decúbito/transporte/transferência do leito; cuidados com tração/gesso; exercícios ativos e passivos de amplitude de movimentos, utilização de mecanismos para posicionamento adequado, auxiliadas/realizadas por um profissional da equipe de enfermagem.

C3 Mudança de decúbito programadas/transporte/transferência do leito; cuidados com tração/gesso, realizadas por 2 ou mais profissionais da equipe de enfermagem, em qualquer freqüência.

\section{Classe D: SUPORTE NUTRICIONAL}

Intervenções para modificar ou manter o estado nutricional (NIC; 2004). Incluem atividades relacionadas à administração de dietas; monitoração da aceitação, da tolerância e da restrição alimentar e controle de peso.

\begin{tabular}{|l|l|}
\hline D1 & Por via oral de forma independente alimentação/hidratação. \\
\hline D2 & $\begin{array}{l}\text { Alimentação/hidratação por via oral (incluindo seio materno e mamadeira) } \\
\text { auxiliada/oferecida pelo acompanhante, nas 24 horas, sob supervisão da equipe } \\
\text { enfermagem. Controle do peso diário; da aceitação alimentar/hídrica realizada pela } \\
\text { equipe de enfermagem. }\end{array}$ \\
\hline D3 & $\begin{array}{l}\text { Alimentação/hidratação por via oral (incluindo mamadeira e copinho) } \\
\text { auxiliada/oferecida pela equipe de enfermagem e controle do peso diário, da aceitação } \\
\text { e da tolerância alimentar/hídrica realizado pela equipe de enfermagem. }\end{array}$ \\
\hline D4 & $\begin{array}{l}\text { Administração da alimentação/hidratação por sondas; controle de peso diário; controle } \\
\text { da restrição alimentar/hídrica realizado pela equipe de enfermagem. }\end{array}$ \\
\hline D5 & $\begin{array}{l}\text { Administração da alimentação/hidratação por via oral para paciente com alteração do } \\
\text { padrão de sucção e/ou deglutição; nutrição parenteral; controle de peso } 2 \text { vezes ao dia, } \\
\text { realizado pela equipe de enfermagem. }\end{array}$ \\
\hline
\end{tabular}




\section{Classe G: CONTROLE DE ELETRÓLITOS E ÁCIDO-BÁSICO}

Intervenções para regular o equilíbrio eletrolítico/ Ácido-básico e prevenir complicações (NIC; 2004). Incluem atividades relacionadas à monitoração e coleta de exames laboratoriais; monitoração de sintomas de alcalose/acidose metabólica e respiratória.

\section{G1 Verificação e controle de glicosúria/cetonúria/glicemia capilar, realizados pela equipe} de enfermagem.

G2 Verificação e monitoração dos níveis de eletrólitos e gases sanguíneos, realizados pela equipe de enfermagem.

G3 Administração de terapia de reidratação oral, realizados pela equipe de enfermagem.

G4 Realização de procedimentos dialíticos, realizados pela equipe de enfermagem.

\section{Classe H: CONTROLE DE DROGAS}

Intervenções para facilitar efeitos desejados de agentes farmacológicos (NIC; 2004).

Atividades que incluem: punção e manutenção de acesso venoso, cuidados na administração e controle de medicamentos.

H1 Administração de medicamentos via oral ou inalatória, com colaboração do paciente/acompanhante.

H2 Administração de medicamentos por sondas ou pelas vias IM/ID/SC com colaboração do paciente/acompanhante.

H3 Punção de acesso venoso e/ou administração de medicamentos endovenosos contínuos ou intermitentes, com colaboração do paciente/acompanhante.

H4 Punção de acesso venoso periférico ou administração de medicamentos, por qualquer via, com resistência do paciente, realizado por mais de um profissional.

H5 Administração de medicação endovenosa por via central ou por via periférica, com necessidade de múltiplas punções nas $24 \mathrm{hs}$, por dificuldade de acesso ou de manutenção.

H6 Administração de drogas vasoativas e ou quimioterápicos e/ou passagem de cateter central de inserção periférica, realizado pelo enfermeiro.

\section{Classe I: CONTROLE NEUROLógICO}

Intervenções para otimizar as funções neurológicas (NIC, 2004). Incluem atividades como: Monitorização do nível de consciência, orientação, reações a estímulos, aplicação de escala de Coma de Glasgow, monitoração da pressão de perfusão cerebral e pressão intracraniana.

\begin{tabular}{|l|l|}
\hline 11 & Atividade Neurológica normal, sem necessidade de vigilância. \\
\hline $\mathbf{1 2}$ & $\begin{array}{l}\text { Observação de sinais e sintomas de hipoatividade/agitação, realizada pelo } \\
\text { acompanhante, nas } 24 \text { horas, orientado e supervisionado pela equipe de enfermagem. }\end{array}$ \\
\hline $\mathbf{1 3}$ & $\begin{array}{l}\text { Monitoração dos padrões de orientação do paciente, realizado pela equipe de } \\
\text { enfermagem. }\end{array}$ \\
\hline $\mathbf{1 4}$ & $\begin{array}{l}\text { Avaliação das reações neurológicas do paciente a estímulos verbal, táctil e nocivo e } \\
\text { aplicação Escala Coma Glasgow até } 2 \text { vezes ao dia. }\end{array}$ \\
\hline $\mathbf{1 5}$ & $\begin{array}{l}\text { Monitoração da pressão de perfusão cerebral ou da pressão intracraniana, aplicação } \\
\text { de Escala Coma de Glasgow mais de 2 vezes ao dia. }\end{array}$ \\
\hline
\end{tabular}




\begin{tabular}{|c|c|}
\hline \multicolumn{2}{|r|}{$\begin{array}{l}\text { Classe K: CONTROLE RESPIRATÓRIO } \\
\text { Intervenções para promover a permeabilidade das vias aéreas e a troca de gases (NIC, } \\
\text { 2004). Incluem atividades relacionadas à administração de oxigenoterapia; controle e } \\
\text { aspiração de vias aéreas; monitorização e cuidados com ventilação mecânica e extubação. }\end{array}$} \\
\hline K1 & $\begin{array}{l}\text { Padrão respiratório normal, sem necessidade de aspiração das vias aéreas ou } \\
\text { oxigenoterapia }\end{array}$ \\
\hline K2 & $\begin{array}{l}\text { Administração de Oxigênio não invasivo de forma intermitente (catéter, tenda, capuz e } \\
\text { máscara de O2) e/ou aspiração das vias aéreas até } 3 \text { vezes em } 24 \text { horas }\end{array}$ \\
\hline K3 & $\begin{array}{l}\text { Administração de Oxigênio não invasivo de forma continua (catéter, tenda, capuz e } \\
\text { máscara de } 02 \text { ), e/ou aspiração das vias aéreas mais que } 3 \text { vezes em } 24 \text { horas. }\end{array}$ \\
\hline K4 & $\begin{array}{l}\text { Administração de oxigênio por Ventilação Mecânica invasiva (tubo endotraqueal) ou } \\
\text { não invasiva (CPAP, BIPAP), com aspirações da cânula/vias áreas em qualquer } \\
\text { freqüência. }\end{array}$ \\
\hline
\end{tabular}

\section{Classe L: Controle dA Pele/ Lesões}

Intervenções para manter ou restaurar a integridade tissular (NIC; 2004). Atividades como: prevenção de lesões e úlceras de pressão; cuidados com locais de incisões cirúrgicas, lesões e ostomias; cuidados na amputação, realização de curativos e monitorização da evolução da lesão.

L1 Limpeza da ferida ou incisão cirúrgica realizada durante o banho pelo paciente/acompanhante.

L2 Utilização de colchões especiais ou acessórios no leito, realização de massagem para prevenção de úlcera de pressão; curativo de lesão, incisão cirúrgica, ostoma, local de inserção de sonda, dreno, cateter, realizada 1 vez ao dia, pela equipe de enfermagem.

L3 Curativo de lesão, incisão cirúrgica, ostoma, local de inserção de sonda, dreno, cateter, realizada 2 vezes ao dia, pela equipe de enfermagem.

L4 Curativo realizado pela enfermagem 3 ou mais vezes ao dia ou curativo de múltiplas lesões, eviscerações ou lesão de grande extensão (queimaduras), realizada pela equipe de enfermagem, em qualquer freqüência, que utilizem mais que 40 minutos para sua realização. 


\begin{tabular}{|l|}
\hline Classe M: TERMO REGULAÇÃo \\
Intervenções para manter a temperatura corporal dentro dos parâmetros normais (NIC; \\
2004). Incluem atividades como controle de temperatura corporal, de incubadora, berço \\
aquecido; aplicação de compressas quentes e frias.
\end{tabular}




\begin{tabular}{|c|c|}
\hline & $\begin{array}{l}\text { s que dão supor } \\
\text { vida. }\end{array}$ \\
\hline & $\begin{array}{l}\text { O: TERAPIA COMPORTAMENTAL } \\
\text { ções para reforçar ou promover comportamentos desejáveis ou alterar } \\
\text { tamentos indesejáveis (NIC; 2004). Incluem atividades como observação do } \\
\text { tamento; estabelecimento de limites; acompanhamento em atividades } \\
\text { recreativas; utilização do brinquedo terapêutico; ensino de habilidades sociais } \\
\text { das; acompanhamento na abstinência de álcool e drogas. }\end{array}$ \\
\hline 01 & ecreativas observadas/acompanhadas pelo acompanhante ou \\
\hline 2 & 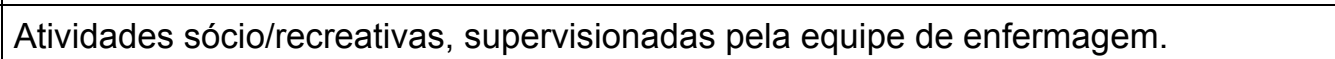 \\
\hline כ3 & cio/recreativas e estabelecimento de limites, \\
\hline 4 & do \\
\hline & $A$ \\
\hline & as (NIC, 2004). Incluem atividades relacionadas aos prc \\
\hline U1 & $\begin{array}{l}\text { rgência como } \\
\text { marca passo, }\end{array}$ \\
\hline U2 & a nas últimas \\
\hline U3 & magem em reanimaçao ce \\
\hline
\end{tabular}




V - CONTROLE DE RISCos
Intervenções para iniciar a atividade de redução de riscos e manter a monitorização
contínua de riscos (NIC; 2004). Incluem atividades como: monitorização de sinais vitais;
atividades relacionadas à prevenção de quedas, fuga, alucinações; contenção física;
controle de alergia e controle de infecção.




\begin{tabular}{|l|l|}
\hline a - CoNTROLE Do SISTEMA DE SAÚDE \\
Intervenções para proporcionar e melhorar os serviços de apoio ao oferecimento de \\
cuidados (NIC; 2004). Incluem atividades relacionadas com assistência em exames em \\
consultas, acompanhamento de estudantes e funcionários; solicitação e avaliação de novos \\
produtos; conferencia de medicação controlada e discussão de caso clínico.
\end{tabular}

\subsection{Perfil das especialistas}

painel de especialistas foi composto por quatro enfermeiras com ampla experiência profissional nas áreas assistencial, no ensino e na pesquisa, garantindo-se a participação de especialistas em pediatria, em Sistema Classificação de pacientes e Classificação das Intervenções de Enfermagem. 
A especialista A, com título de Mestre em enfermagem e especialização em pediatria, é graduada há 20 anos, e tem experiência na prática assistencial e gerencial em unidades de clínica pediátrica e terapia intensiva pediátrica e neonatal. A avaliadora $\mathrm{B}$, com título de doutora, graduada há 25 anos, trabalha como docente em universidade pública, onde desenvolve atividades de ensino e pesquisa na área de pediatria. A especialista C, professora titular de universidade pública, graduada há 27 anos, desenvolve atividades de ensino e de pesquisa que incluem as temáticas relacionadas aos sistemas padronizados de linguagem. A especialista D, livre docente de universidade pública, graduada há 23 anos, também atua no ensino e no desenvolvimento de pesquisas na área de dimensionamento de pessoal de recursos humanos em enfermagem e Sistema de Classificação de pacientes.

\subsection{Análise das especialistas}

As respostas, comentários e sugestões das especialistas foram analisadas, verificando-se que houve um consenso quanto à pertinência dos domínios e classes, bem como das intervenções e atividades relacionadas em cada classe, visto que não foram sugeridas inclusão ou exclusão de domínios e classes no instrumento.

As especialistas apontaram algumas atividades e intervenções que não estavam descritas de forma clara e objetiva e que nem sempre indicavam níveis crescentes, de acordo com o tempo estimado para a sua 
realização. Todas consideraram que as atividades descritas eram relevantes e representavam a prática da assistência da enfermagem pediátrica.

As principais sugestões referiram-se à:

- alteração do título do instrumento de "Instrumento de Classificação de Pacientes Pediátricos" para "Instrumento para Identificação da Carga de Trabalho da Equipe de Enfermagem em unidades pediátricas", esta sugestão foi realizada considerando que o objetivo do instrumento não é classificar o paciente e sim, identificar a carga de trabalho da equipe de enfermagem;

- exclusão da relação de intervenções e atividades que acompanhavam a definição das classes, uma vez que estas já estavam descritas nos subitens de cada classe, indicando as ações desenvolvidas na prática assistencial;

- padronização do estilo de redação de forma a descrever as ações de enfermagem e não o perfil assistencial do paciente;

- exclusão do dos itens que retratavam independência do paciente em relação à equipe de enfermagem e as atividades realizadas pelo acompanhante, uma vez que não resultam em dispêndio de tempo para a equipe de enfermagem;

- exclusão, da descrição das ações, a indicação de que as atividades estavam sendo desenvolvidas pela equipe de enfermagem, já que essas ações sempre serão realizadas pela mesma; 
- exclusão da indicação da função do profissional que executa a ação, para não restringir a realização da atividade a uma categoria;

- manutenção do mesmo número de itens para todas as classes;

- considerar auxilio ou realização no mesmo nível pois, nas duas situações, o profissional precisa estar disponível e permanecer junto ao paciente;

- inclusão na Classe $\mathrm{E}$ de atividades relativas a náuseas;

- separação das ações indicadas em alguns itens de várias classes, com a finalidade de caracterizar melhor o tempo utilizado para a execução.

\subsection{Reconstrução do instrumento}

Frente a avaliação das especialistas, realizou-se as modificações pertinentes no instrumento, conforme demonstrado a seguir: 


\title{
Instrumento para identificação da carga de trabalho da equipe de enfermagem de unidades pediátricas
}

\author{
Domínio 1: FISIOLÓGıCo BÁsıCo \\ Cuidados que dão suporte ao funcionamento físico do organismo. (NIC, 2004).
}

Classe A: Controle da AtividAde e exercício

Intervenções para organizar ou auxiliar a atividade física e a conservação e gasto de energia (NIC, 2004).

A1 Controle da atividade física.

A2 Auxílio na movimentação/deambulação por um profissional de enfermagem.

A3 Auxílio na movimentação/deambulação por 2 ou mais ou profissionais de enfermagem.

\section{Classe B: CONTROLE dAS ELIMINAÇÕES}

Intervenções para estabelecer e manter padrões de eliminação intestinal e urinária normais e controlar complicações resultantes de padrões alterados (NIC, 2004).

B1 Realização de sondagem vesical de demora em algum período.

B2 Auxílio no uso do vaso sanitário/comadre/urinol ou troca de fraldas/higiene perineal em pacientes com freqüência normal das eliminações.

B3 Sondagem vesical intermitente, até 4 vezes nas 24 horas, ou controle do volume das eliminações.

B4 Auxílio no uso do vaso sanitário/comadre/urinol ou troca de fraldas/higiene perineal em pacientes com aumento da freqüência das eliminações. 


\section{Classe C: CONTROLE DA IMOBILIDADE \\ Intervenções para controlar a restrição de movimentos corporais e as seqüelas (NIC, 2004). \\ C1 Mudança de decúbito/ transporte/ transferência do leito auxiliada/realizada por um profissional de enfermagem. \\ C2 Cuidados com posicionamento/tração/gesso; exercícios ativos e passivos de amplitude de movimentos auxiliados/realizados por um profissional da equipe de enfermagem. \\ C3 Mudança de decúbito programadas/transporte/transferência do leito; cuidados com posicionamento/tração/gesso auxiliado/realizado por 2 ou mais profissionais de enfermagem, em qualquer freqüência.}

\section{Classe D: SUPORTE NUTRICIONAL}

Intervenções para modificar ou manter o estado nutricional (NIC, 2004).

D1 Auxílio ou administração da alimentação/hidratação por via oral (incluindo mamadeira e copinho); controle do peso diário, da aceitação e da tolerância alimentar/hídrica.

D2 Administração da alimentação/hidratação por sonda ou por via oral para paciente com alteração do padrão de sucção e/ou deglutição; nutrição parenteral; controle de peso 2 ou mais vezes nas 24 horas.

\section{Classe E: PROMOÇÃo do CONFORTO Físıco}

Intervenções para promover conforto utilizando técnicas físicas (NIC, 2004).

\begin{tabular}{l|l}
\hline E1 & Monitoração de náusea, vômitos e dor. \\
\hline E2 & Aplicação de escalas para mensuração da dor. \\
\hline E3 & $\begin{array}{l}\text { Implementação de medidas para controle e alivio da náusea, vomito e dor, tais como: } \\
\text { aplicação de calor/frio/massagens/musicoterapia/terapia de jogos/acupressão; } \\
\text { promoção do sono e repouso. }\end{array}$ \\
\hline
\end{tabular}

\section{Classe F: FACILITAÇÃo do AUTO CUIDADO}

Intervenções para proporcionar ou auxiliar nas atividades de rotina de vida diária (NIC, 2004).

F1 Banho de chuveiro, banheira ou cadeira; troca de roupas, higiene oral e higiene íntima; auxílio para o sono e repouso, realizado por um profissional de enfermagem.

F2 Banho na incubadora ou no leito, realizado por um profissional de enfermagem.

F3 Banho no leito, higiene íntima realizado por dois ou mais profissionais de enfermagem. 


\begin{tabular}{|c|c|}
\hline \multicolumn{2}{|c|}{ Domínio 2: FISIOLÓGıCO COMPLEXO } \\
\hline \multicolumn{2}{|r|}{$\begin{array}{l}\text { Classe G:- CONTROLE DE ELETRÓLITOS E ÁcIDO-BÁSıco } \\
\text { Intervenções para regular o equilíbrio eletrolítico/ ácido-básico e prevenir complicações } \\
(\mathrm{NIC}, 2004) \text {. }\end{array}$} \\
\hline G1 & Verificação e controle de glicosúria/cetonúria/glicemia capilar. \\
\hline G2 & Verificação e monitoração dos níveis de eletrólitos e \\
\hline G3 & Administração de terapia de reidratação oral. \\
\hline G4 & Realiz \\
\hline \multicolumn{2}{|r|}{$\begin{array}{l}\text { Classe H: CONTROLE DE DROGAS } \\
\text { Intervenções para facilitar efeitos desejados de agentes farmacológicos (NIC, 2004). }\end{array}$} \\
\hline H1 & Administração de medicamentos via oral/inalatória/sondas. \\
\hline H2 & Administração de medicamentos pelas vias IM/ID/SC. \\
\hline H3 & $\begin{array}{l}\text { Administração de medicamentos endovenosos por via central ou por via periférica } \\
\text { contínuos ou intermitentes. }\end{array}$ \\
\hline H4 & $\begin{array}{l}\text { Administração de medicamentos, por qualquer via, com resistência do paciente, } \\
\text { realizado por dois ou mais profissional de enfermagem. }\end{array}$ \\
\hline H5 & Administração de drogas vasoativas ou quimioterápicos. \\
\hline \multicolumn{2}{|r|}{$\begin{array}{l}\text { Classe I: CONTROLE NEUROLÓGıCO } \\
\text { Intervenções para otimizar as funções neurológicas (NIC, 2004). }\end{array}$} \\
\hline 11 & $\begin{array}{l}\text { Observação de sinais e sintomas de hipoatividade/agitação;monitoração dos padrões } \\
\text { de orientação do paciente. }\end{array}$ \\
\hline 12 & $\begin{array}{l}\text { Avaliação das reações neurológicas do paciente a estímulos verbal, táctil e doloroso } \\
\text { ou aplicação Escala Coma Glasgow até } 2 \text { vezes nas } 24 \text { horas. }\end{array}$ \\
\hline 13 & $\begin{array}{l}\text { u da pressão intracraniana; aplicação } \\
\text { las } 24 \text { horas. }\end{array}$ \\
\hline
\end{tabular}




\begin{tabular}{|c|c|}
\hline \multicolumn{2}{|r|}{ Slasse K: CONTROLE RESPIRATÓRIO } \\
\hline $\mathrm{K} 1$ & 3 veres on \\
\hline K2 & capuz e máscara de O2), ou \\
\hline 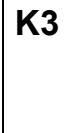 & $\begin{array}{l}\text { não invasiva (CPAP, BIPAP), com aspirações da cânula/vias áre } \\
\text { freqüência. }\end{array}$ \\
\hline \multicolumn{2}{|c|}{ Classe L: Controle dA PeLE/ Lesões } \\
\hline 1 & 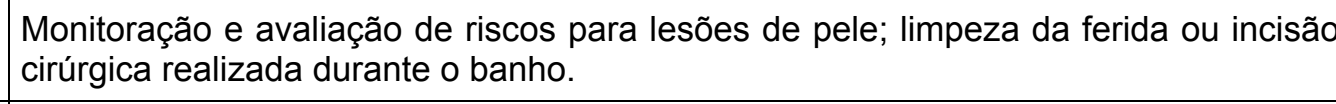 \\
\hline 2 & $\begin{array}{l}\text { para prevenção de úlcera por pressão; curativo de lesão, i } \\
\text { local de inserção de sonda, dreno, cateter, realizada } 1 \text { vez a }\end{array}$ \\
\hline L3 & $\begin{array}{l}\text { lesão, incisão cirúrgica, ostoma, local de inserção de sonda, dreno, } \\
\text { izada } 2 \text { vezes ao dia. }\end{array}$ \\
\hline L4 & $\begin{array}{l}\text { Curativo realizado } 3 \text { ou mais vezes ao dia ou curativo de múltiplas lesões, } \\
\text { eviscerações ou lesão de grande extensão (queimaduras), que utilizem mais que } 40 \\
\text { minutos para sua realização, em qualquer freqüência }\end{array}$ \\
\hline \multicolumn{2}{|r|}{$\begin{array}{l}\text { Classe M: TERMORREGULAÇÃo } \\
\text { Intervenções para manter a temperatura corporal dentro dos parâmetros normais (NIC, } \\
\text { 2004). }\end{array}$} \\
\hline M1 & Monitoração da temperatura corpórea, até 3 vezes a \\
\hline M2 & ão da temperatura corpórea, mais que 3 vezes ao dia. \\
\hline M3 & $\begin{array}{l}\text { Monitoração contínua da temperatura corpórea e/ou utilização e controle de } \\
\text { equipamentos (incubadora, berço aquecido, colchões para aquecimento e } \\
\text { resfriamento) para manutenção/regulação da temperatura corporal. }\end{array}$ \\
\hline M4 & b. \\
\hline
\end{tabular}




\begin{tabular}{|l|l|}
\hline \multicolumn{2}{|l|}{ Classe N: ConTROLE DA PERFUSÃo TISSULAR } \\
Intervenções para otimizar a circulação do sangue e líquidos aos tecidos, (NIC, 2004). \\
\hline N1 & $\begin{array}{l}\text { Punção de acesso venoso periférico para administração por via endovenosa de } \\
\text { medicamentos/ líquidos para manutenção da volemia; monitoração de sinais e } \\
\text { sintomas de sangramento. }\end{array}$ \\
\hline N2 & $\begin{array}{l}\text { Múltiplas punções venosas nas 24 horas por dificuldade de acesso venoso ou da sua } \\
\text { manutenção. }\end{array}$ \\
\hline N3 & $\begin{array}{l}\text { Administração rápida de líquidos por via endovenosa ou intra-óssea para reposição } \\
\text { da volemia. }\end{array}$ \\
\hline N4 & $\begin{array}{l}\text { Monitoração da pressão venosa central, pressão arterial média, perfusão periférica e } \\
\text { pressão capilar pulmonar. }\end{array}$ \\
\hline N5 & $\begin{array}{l}\text { Administração de hemoderivados; cuidados com aparelhos de suporte circulatório } \\
\text { mecânico; inserção de Cateter Central de Inserção Periférica nas últimas 24 horas. }\end{array}$ \\
\hline Domínio 3: ComPORTAMENTAL \\
Cuidados que dão suporte ao funcionamento psicossocial e facilitam mudanças no estilo de \\
vida. (NIC, 2004).
\end{tabular}




\begin{tabular}{|c|c|}
\hline Cuic & $\begin{array}{l}\text { ínio 4: SEGURANÇA } \\
\text { ados que dão suporte à proteção contra danos. (NIC, 2004) }\end{array}$ \\
\hline $\begin{array}{l}\text { nte } \\
\text { isic }\end{array}$ & $\begin{array}{l}\text { TROLE DE CRISE } \\
\text { ões para oferecer ajuda imediata, a curto prazo, em crises psi } \\
\text { as (NIC, 2004). }\end{array}$ \\
\hline U1 & $\begin{array}{l}\text { Auxílio em procedimentos de urgência/emergência como intubação, drenagem de } \\
\text { tórax, passagem de cateter, inserção de marca passo, cirurgia de } \\
\text { urgência/emergência, nas últimas } 24 \text { horas. }\end{array}$ \\
\hline U2 & en \\
\hline U3 & Participação em reanimação cardiorespiratória e cardioversão, nas últimas 24 horas. \\
\hline & NTROLE DE RISCOS \\
\hline V1 & $\begin{array}{l}\text { C e PA, até } 3 \text { vezes nas } 24 \text { horas; observação do } \\
\text { das para prevenir queda/fuga/suicídio }\end{array}$ \\
\hline $\mathbf{V 2}$ & $\begin{array}{l}\text { Monitorização de FR, FC e PA realizada pela enfermagem mais que } 3 \text { vezes ao dia; } \\
\text { cuidados com paciente alérgico; implementação de precaução de contato/ } \\
\text { gotículas/aerossóis. }\end{array}$ \\
\hline V3 & $\begin{array}{l}\text { FR, FC e PA e saturação de oxigênio; vigilância contínua } \\
\text { de queda/fuga/suicídio; contenção física do paciente em }\end{array}$ \\
\hline & 4). \\
\hline & AÇÃo COM O SISTEMA DE SAÚdE \\
\hline Y1 & ientação ao paciente/cuidador para a realização de ativi \\
\hline Y2 & $\begin{array}{l}\text { Treinamento do paciente/cuidador para realização de atividade de autocuidado no } \\
\text { domicilio. }\end{array}$ \\
\hline Y3 & quação do ambiente às necessic \\
\hline
\end{tabular}




\begin{tabular}{|c|c|}
\hline & $\begin{array}{l}\text { TROLE DO SISTEMA DE SAÚDE } \\
\text { Ções para proporcionar e melhorar os serviços de apoio ao } \\
\text { S (NIC, 2004). }\end{array}$ \\
\hline a1 & $\begin{array}{l}\text { Conferência e reposição de medicamento controlado utilizado pelo paciente, em } \\
\text { algum período. }\end{array}$ \\
\hline a2 & $\begin{array}{l}\text { Solicitação e avaliação de novos produtos/equipamentos para utilização pelo } \\
\text { paciente. }\end{array}$ \\
\hline a3 & $\begin{array}{l}\text { fermagem ou estudante para } \\
\text { algum período. }\end{array}$ \\
\hline a4 & $\begin{array}{l}\text { Acompanhamento do paciente por um profissional de enfermagem durante } \\
\text { realização de exames radiológicos e endoscópicos dentro da instituição, em algum } \\
\text { período. }\end{array}$ \\
\hline a5 & $\begin{array}{l}\text { eparo e acompanhamento de paciente a outra instituição para realização de } \\
\text { ames/consultas em algum período. }\end{array}$ \\
\hline & LE DAS INF \\
\hline b1 & ersos ou \\
\hline D & em. \\
\hline b3 & $S$ \\
\hline
\end{tabular}

O instrumento reconstruído foi encaminhado ao grupo de especialistas para nova apreciação, acompanhado de carta-convite para participação em reunião (Anexo F), com a finalidade de discutir e estabelecer um consenso sobre o conteúdo do novo instrumento.

A reunião de consenso foi agendada de acordo com a disponibilidade das especialistas.

\subsection{Consenso das especialistas}

A reunião para consenso do instrumento foi realizada aos sete dias do mês de julho de 2006, na Escola de Enfermagem da Universidade de São 
Paulo, e teve duração aproximada de três horas. Participaram da reunião as quatro especialistas, a pesquisadora e a orientadora.

A reunião teve início com a solicitação de consentimento para que a reunião fosse gravada, e com a apresentação da síntese das mudanças realizadas no instrumento.

Prosseguiu-se com a discussão do conteúdo do instrumento, principalmente, no que se referia às intervenções e atividades incluídas em cada classe, procurando se obter um consenso sobre a determinação dos níveis crescentes, de acordo com o tempo estimado para a sua realização.

Percebeu-se, no entanto, que algumas especialistas, ao avaliar os níveis crescentes das intervenções e atividades, levavam em consideração a complexidade técnica das mesmas e não o tempo estimado para a sua realização. Dessa forma esses aspectos foram discutidos e esclarecidos.

Retomada a discussão para avaliação das intervenções e atividades, em níveis crescentes, refletiu-se sobre a importância de determinar esse aspecto na atual etapa do estudo. Considerando que a pesquisara pretende realizar nova pesquisa, com o objetivo de determinar o tempo despendido na execução de cada intervenção e atividade descrita, optou-se por prosseguir com a análise, separando em diferentes itens as intervenções e atividades que indicavam ações de natureza distintas, ou que aparentemente representavam carga de trabalho diferente.

Foram revisados os conteúdos de todas as classes, item a item, até obtenção de consenso. 
As outras alterações realizadas no instrumento na reunião de consenso se referiram à:

- o termo "período" foi substituído por "turno", por referir-se a cada uma das divisões do horário de trabalho;

- o termo "ou" passou a ser utilizado somente quando indicava substituição das intervenções ou atividades;

- os termos "verificação e monitoração" da Classe G, foram substituídos por "controle" por melhor indicar a ação;

- exclusão de indicações que complementavam a descrição de algumas intervenções e atividades, porém, não interferiam na carga de trabalho, tais como: "por via central ou periférica" da Classe N; "com resistência do paciente" da Classe $\mathrm{H}$; "aplicação de escala de Glasgow" da Classe I e "estabelecimento de limites" da Classe O; "limpeza da incisão cirúrgica" e "utilização de colchões especiais ou acessórios no leito" da Classe L e "cuidados com paciente alérgico" da Classe "v".

- inclusão da atividade "manter a criança no colo" na Classe R, no sentido de indicar a necessidade de acalentar a criança, uma importante ação realizada em unidades pediátricas;

- indicação em diferentes itens, das ações de natureza distintas ou que aparentemente tinham carga de trabalho diferentes; 
- exclusão da atividade "transporte" da Classe C, por está sendo considerada como parte da atividade de encaminhamento de paciente na Classe "a";

- exclusão das atividades que exemplificavam a implementação de medidas de controle e alivio da náusea, vômito e dor da Classe E, para dar maior objetividade ao instrumento;

- exclusão da atividade "auxilio no sono e repouso" da Classe F mantendo-a na Classe E.

Nas Classes A, U e Y, não foram realizadas alterações.

O instrumento foi novamente modificado, conforme o consenso estabelecido pelas especialistas.

\subsection{Proposta final do instrumento}

O instrumento final manteve-se constituído por cinco domínios e 20 classes, porém as classes passaram a ser constituídas de três a dez níveis, conforme demonstrado a seguir. 


\section{Instrumento para identificação da carga de trabalho da equipe de enfermagem de unidades pediátricas}

\begin{tabular}{|c|c|}
\hline \multicolumn{2}{|c|}{ Domínio 1: FISIOLÓGıCo BÁsıCo } \\
\hline \multicolumn{2}{|r|}{$\begin{array}{l}\text { Classe A: CONTROLE DA ATIVIDADE E EXERCícIo } \\
\text { Intervenções para organizar ou auxiliar a atividade física e a conservação e gasto de } \\
\text { energia (NIC, 2004). }\end{array}$} \\
\hline 1 & 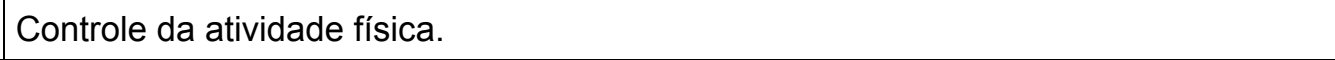 \\
\hline A2 & Auxílio na movimentação/deambulação por um profissional de enfermagem. \\
\hline A3 & $\begin{array}{l}\text { Auxílio na movimentação/deambulação por } 2 \text { ou mais ou profissionais de } \\
\text { enfermagem. }\end{array}$ \\
\hline \multicolumn{2}{|r|}{$\begin{array}{l}\text { Classe B: CONTROLE DAS ELIMINAÇÕES } \\
\text { Intervenções para estabelecer e manter padrões de eliminação intestinal e urinária normais } \\
\text { e controlar complicações resultantes de padrões alterados (NIC, 2004). }\end{array}$} \\
\hline B1 & Realização de sondagem vesical c \\
\hline B2 & $\begin{array}{l}\text { Troca de fraldas/higiene perineal em pacientes com freqüência normal das } \\
\text { eliminações. }\end{array}$ \\
\hline $\mathrm{B}^{3}$ & $\begin{array}{l}\text { Auxílio } \\
\text { das elin }\end{array}$ \\
\hline B4 & Contr \\
\hline B5 & é 4 vezes nas 24 horas. \\
\hline B6 & $\begin{array}{l}\text { Troca de fraldas/higiene perineal em pacientes com aumento da freqüência das } \\
\text { eliminações. }\end{array}$ \\
\hline B7 & $\begin{array}{l}\text { Auxílio no uso do vaso sanitário/comadre/urinol a pacientes com aumento da } \\
\text { freqüência das eliminações. }\end{array}$ \\
\hline
\end{tabular}




\begin{tabular}{|c|c|}
\hline \multicolumn{2}{|c|}{ Classe C: ConTROLE DA IMOBILIDADE } \\
\hline C1 & $\begin{array}{l}\text { Cuidados com posicionamento/tração/gesso realizados por um profissional de } \\
\text { enfermagem. }\end{array}$ \\
\hline $\mathrm{C} 2$ & $\begin{array}{l}\text { Mudança de decúbito/ transferência do leito auxiliada/realizada por um profissional } \\
\text { de enfermagem. }\end{array}$ \\
\hline C3 & $\begin{array}{l}\text { Exercícios ativos e passivos de amplitude de movimentos auxiliados/realizados por } \\
\text { um profissional de enfermagem. }\end{array}$ \\
\hline C4 & $\begin{array}{l}\text { Mudança de decúbito /transferência do leito realizado por } 2 \text { ou mais profissionais de } \\
\text { enfermagem. }\end{array}$ \\
\hline C5 & $\begin{array}{l}\text { Cuidados com posicionamento/tração/gesso auxiliado/realizados por } 2 \text { ou mais } \\
\text { profissionais de enfermagem. }\end{array}$ \\
\hline \multicolumn{2}{|c|}{ Classe D: SUPORTE NUTRICIONAL } \\
\hline D1 & Controle da aceitação e da tolerância alimentar/hídrica. \\
\hline D2 & Controle do peso diário. \\
\hline D3 & $\begin{array}{l}\text { Auxílio ou administração da alimentação/hidratação por via oral (incluindo mamadeira } \\
\text { e copinho). }\end{array}$ \\
\hline D4 & Controle do peso 2 ou mais vezes nas 24 horas. \\
\hline D5 & Administração da alimentação/hidratação por sondas. \\
\hline D6 & $\begin{array}{l}\text { Administração da alimentação/hidratação por via oral para paciente com alteração do } \\
\text { padrão de sucção e/ou deglutição. }\end{array}$ \\
\hline D7 & Nutri \\
\hline
\end{tabular}




\begin{tabular}{|c|c|}
\hline Inte & para promover conforto uti \\
\hline E1 & Monitoração de náusea, vômitos. \\
\hline E2 & Monitoração e aplicação de escalas para mensuração da dor. \\
\hline E3 & Implementação de medidas para controle e alivio da náusea, vomito e dor. \\
\hline E4 & Promoção do sono e repouso. \\
\hline $\begin{array}{l}\text { Cla: } \\
\text { Inte } \\
200\end{array}$ & $\begin{array}{l}\text { se F: FACILITAÇÃo DO AUTO CUIDADO } \\
\text { /enções para proporcionar ou auxiliar nas atividades de rotina de vida diária (NIC, }\end{array}$ \\
\hline F1 & Auxílio/realização de higiene oral \\
\hline $\mathbf{F 2}$ & Auxílio/realização de higiene íntima \\
\hline F3 & Auxílio /realização de troca de roupas \\
\hline F4 & $\begin{array}{l}\text { Banho de chuveiro, banheira ou cadeira auxiliado/realizado por um profissional de } \\
\text { enfermagem. }\end{array}$ \\
\hline F5 & Banho na incubadora. \\
\hline F6 & $\begin{array}{l}\text { Banho de chuveiro, banheira ou cadeira auxiliado/realizado por } 2 \text { ou mais } \\
\text { profissionais de enfermagem. }\end{array}$ \\
\hline F7 & Banho no leito, realizado por um profissional de enfermagem. \\
\hline F8 & Banho no leito realizado por dois ou mais profissionais de enfermagem. \\
\hline Don & $\begin{array}{l}\text { ínio 2: FISIOLÓGıCo COMPLEXo } \\
\text { ados que dão suporte à regulação homeostática . (NIC, 2004). }\end{array}$ \\
\hline $\begin{array}{l}\text { Cla } \\
\text { Inte } \\
\text { (NIC }\end{array}$ & $\begin{array}{l}\text { Se G:- CONTROLE DE ELETRÓLITOS E ÁCIDO-BÁSICo } \\
\text { /enções para regular o equilíbrio eletrolítico/ ácido-básico e prevenir complicações } \\
\text { 2004). }\end{array}$ \\
\hline G1 & Controle de glicosúria/cetonúria. \\
\hline G2 & Controle de glicemia capilar \\
\hline G3 & Controle dos níveis de eletrólitos e gases sanguíneos. \\
\hline G4 & Administração de terapia de reidratação oral. \\
\hline G5 & Realização de procedimentos dialíticos. \\
\hline
\end{tabular}




\begin{tabular}{|c|c|}
\hline Inter & $\begin{array}{l}\text { Se H: CONTROLE DE DROGAS } \\
\text { enções para facilitar efeitos desejados de agentes farmacológicos (NIC, 2004). }\end{array}$ \\
\hline H1 & Administração de medicamentos por sondas. \\
\hline $\mathrm{H} 2$ & Administração de medicamentos por via oral. \\
\hline H3 & Administração de medicamentos por via inalatória. \\
\hline H4 & Administração de medicamentos pelas vias IM/ID/SC. \\
\hline H5 & Administração de medicamentos endovenosos contínuos. \\
\hline H6 & Administração de medicamentos endovenosos intermitentes. \\
\hline H7 & $\begin{array}{l}\text { Administração de medicamentos, por qualquer via, realizado por dois ou mais } \\
\text { profissionais de enfermagem. }\end{array}$ \\
\hline H8 & Administração de drogas vasoativas ou antineoplásicas. \\
\hline & $\begin{array}{l}\text { Se I: CONTROLE NEUROLÓGICO } \\
\text { Ienções para otimizar as funções neurológicas (NIC, 2004). }\end{array}$ \\
\hline 11 & Controle de sinais e sintomas de hipoatividade/agitação \\
\hline 12 & Controle dos padrões de orientação do paciente. \\
\hline 13 & Avaliação das reações neurológicas do paciente a estímulos verbal, táctil e doloroso. \\
\hline 14 & Monitoração da pressão intracraniana. \\
\hline & $\begin{array}{l}\text { Se K: CONTROLE RESPIRATÓRIO } \\
\text { lenções para promover a permeabilidade das vias aéreas e a troca de gases (NIC, }\end{array}$ \\
\hline K1 & Aspiração das vias aéreas até 3 vezes em 24 horas. \\
\hline K2 & Aspiração das vias aéreas mais que 3 vezes em 24 horas. \\
\hline K3 & Administração de Oxigênio não invasivo (catéter, tenda, capuz ou máscara de O2) \\
\hline K4 & Controle das vias aéreas do paciente em ventilação mecânica não invasiva. \\
\hline K5 & iva. \\
\hline
\end{tabular}




\begin{tabular}{|c|c|}
\hline \multicolumn{2}{|c|}{ Classe L: ContRole dA PeLE/ LeS } \\
\hline L1 & Monitoração e avaliação de riscos para lesões de pele. \\
\hline L2 & Realização de massagens. \\
\hline L3 & $\begin{array}{l}\text { Curativo de lesão, incisão cirúrgica, ostoma, local de inserção de sonda, dreno, } \\
\text { cateter, realizada } 1 \text { vez ao dia. }\end{array}$ \\
\hline L4 & $\begin{array}{l}\text { Curativo de lesão, incisão cirúrgica, ostoma, local de inserção de sonda, dreno, } \\
\text { cateter, realizada } 2 \text { vezes ao dia. }\end{array}$ \\
\hline L5 & $\begin{array}{l}\text { Curativo de lesão, incisão cirúrgica, ostoma, local de inserção de sonda, dreno, } \\
\text { cateter, realizada } 3 \text { vez ao dia. }\end{array}$ \\
\hline L6 & $\begin{array}{l}\text { Curativo de múltiplas lesões, eviscerações ou lesão de grande extensão } \\
\text { (queimaduras),que utilizem mais que } 40 \text { minutos para sua realização, em qualquer } \\
\text { freqüência. }\end{array}$ \\
\hline \\
\hline M1 & Monitoração da temperatura corpórea até 3 vezes ao dia. \\
\hline M2 & Monitoração da temperatura corpórea, mais que 3 vezes ao dia. \\
\hline M3 & Monitoração contínua da temperatura corpórea. \\
\hline M4 & $\begin{array}{l}\text { Utilização e controle de equipamentos para aquecimento e resfriamento da } \\
\text { temperatura corpórea. }\end{array}$ \\
\hline M5 & Aplicação de compressas frias ou quentes. \\
\hline M6 & $\begin{array}{l}\text { Realização de banho de imersão para regulação da temperatura corporal em algum } \\
\text { turno. }\end{array}$ \\
\hline
\end{tabular}




\begin{tabular}{|l|l|}
\hline \multicolumn{2}{|l|}{ Classe N: CoNTROLE DA PERFUSÃo TISsULAR } \\
Intervenções para otimizar a circulação do sangue e líquidos aos tecidos (NIC, 2004). \\
\hline N1 & Monitoração da perfusão periférica /sinais e sintomas de sangramento. \\
\hline N2 & $\begin{array}{l}\text { Punção de acesso venoso periférico para administração por via endovenosa de } \\
\text { medicamentos/ líquidos para manutenção da volemia. }\end{array}$ \\
\hline N3 & Múltiplas punções venosas nas 24 horas. \\
\hline N4 & $\begin{array}{l}\text { Administração rápida de líquidos por via endovenosa ou intra-óssea para reposição } \\
\text { da volemia. }\end{array}$ \\
\hline N5 & Monitoração da pressão venosa central. \\
\hline N6 & Monitoração da pressão arterial média. \\
\hline N7 & Monitoração da pressão capilar pulmonar. \\
\hline N8 & Administração de hemoderivados. \\
\hline N9 & Cuidados com aparelhos de suporte circulatório mecânico. \\
\hline N10 & Inserção de Cateter Central de Inserção Periférica nas últimas 24 horas. \\
\hline Domínio 3: ComPORTAMENTAL \\
Cuidados que dão suporte ao funcionamento psicossocial e facilitam mudanças no estilo de \\
vida (NIC, 2004). \\
\hline Classe O: TERAPIA ComPORTAMENTAL \\
Intervenções para reforçar ou promover comportamentos desejáveis ou alterar \\
comportamentos indesejáveis (NIC, 2004). \\
\hline O1 & Supervisão de atividades sócio/recreativas. \\
\hline O2 & Acompanhamento em atividades sócio/recreativas. \\
\hline O3 & Vigilância constante do paciente/ambiente. \\
\hline O4 & Atendimento em situações de agitação e/ou agressão e abstinência. \\
\hline O5 & Aplicação do brinquedo terapêutico. \\
\hline
\end{tabular}




\section{Classe R: ASSISTÊNCIA NO ENFRENTAMENTO}

Intervenções para auxiliar o outro a contar com seus pontos fortes,adaptar-se a uma mudança de função ou alcançar um nível mais elevado de funcionamento (NIC, 2004).

\begin{tabular}{|l|l|}
\hline R1 & Encaminhamento do paciente/família aos serviços de apoio social/espiritual. \\
\hline R2 & Apoio ao paciente/família para adaptação à situação de doença. \\
\hline R3 & Esclarecimento/orientação sobre diagnóstico/tratamento/procedimento específico. \\
\hline R4 & $\begin{array}{l}\text { Participação do enfermeiro em reuniões com paciente/família/equipe multidisciplinar } \\
\text { para informação, tomada de decisão, soluções de problemas evidenciados durante a } \\
\text { internação. }\end{array}$ \\
\hline R5 & $\begin{array}{l}\text { Permanência de um profissional de enfermagem junto ao paciente/família durante } \\
\text { períodos de ansiedade e/ou fases de sofrimento/ manter a criança no colo. }\end{array}$ \\
\hline
\end{tabular}

\section{Domínio 4: SEgurança}

Cuidados que dão suporte à proteção contra danos. (NIC, 2004)

\section{U - CONTROLE DE CRISE}

Intervenções para oferecer ajuda imediata, a curto prazo, em crises psicológicas e fisiológicas (NIC, 2004).

U1 Auxílio em procedimentos de urgência/emergência como intubação, drenagem de tórax, passagem de cateter, inserção de marca passo, cirurgia de urgência/emergência, nas últimas 24 horas.

U2 Atendimento em crise convulsiva nas últimas 24 horas.

U3 Participação em reanimação cardiorespiratória e cardioversão, nas últimas 24 horas.

V - CONTROLE DE RISCOS

Intervenções para iniciar a atividade de redução de riscos e manter a monitorização contínua de riscos (NIC, 2004).

V1 Monitorização de FR, FC e PA, até 3 vezes nas 24 horas.

V2 Monitorização de FR, FC e PA, mais que 3 vezes nas 24 horas.

V3 Implementação e controle de precaução de contato/ gotículas/aerossóis.

V4 Monitorização de FR, FC e PA e saturação de oxigênio.

V5 Adoção de medidas para prevenir queda/fuga/suicídio.

V6 Contenção física do paciente em algum turno. 


\begin{tabular}{|c|c|}
\hline \multicolumn{2}{|c|}{ omínio 6: SISTEMA DE SAÚDE } \\
\hline \multicolumn{2}{|r|}{$\begin{array}{l}\text { Intervenções para facilitar a interface entre paciente/família e o sistema de atendimento à } \\
\text { saúde (NIC, 2004). }\end{array}$} \\
\hline Y1 & $\begin{array}{l}\text { Orientação ao paciente/cuidador para a realização de atividades de autocuidado no } \\
\text { domicílio. }\end{array}$ \\
\hline 2 & nic \\
\hline 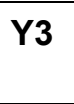 & ito \\
\hline \multicolumn{2}{|r|}{$\begin{array}{l}\text { Intervenções para proporcionar e melhorar os serviços de apoio ao oferecimento de } \\
\text { cuidados (NIC, 2004). }\end{array}$} \\
\hline a1 & $\begin{array}{l}\text { onferência e reposição de medicamentos controlados utilizados pelo paciente, e } \\
\text { gum turno. }\end{array}$ \\
\hline $\mathrm{a2}$ & ão e avaliação de novos produtos/equipamentos para utilização pelo \\
\hline 3 & ou est \\
\hline a4 & cais, \\
\hline $\mathrm{a} 5$ & . \\
\hline \multicolumn{2}{|r|}{$\begin{array}{l}\text { b - CONTROLE DAS INFORMAÇõES: intervenções para facilitar a comunicação sobre os } \\
\text { cuidados de saúde (NIC, 2004). }\end{array}$} \\
\hline b1 & 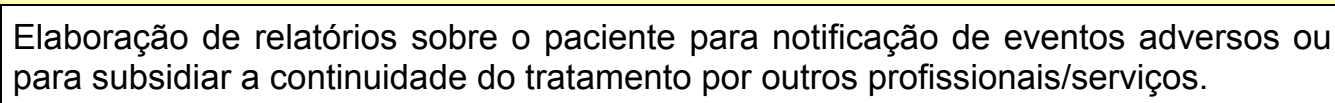 \\
\hline b2 & Aplic \\
\hline b3 & $\begin{array}{l}\text { Participação de profissional de enfermagem em reuniões para avaliação de } \\
\text { cuidados. }\end{array}$ \\
\hline 44 & los de pesquisa a serem desenvolvidos jun \\
\hline
\end{tabular}


Considerações finais 


\section{Considerações finais}

O desenvolvimento desta pesquisa possibilitou a reflexão e a análise dos aspectos relacionados, diretamente, à determinação da carga de trabalho da equipe de enfermagem.

O método utilizado para o desenvolvimento da pesquisa permitiu maior aproximação com a realidade assistencial do paciente pediátrico, contribuindo para a compreensão dos processos assistenciais e gerenciais envolvidos no dimensionamento de pessoal de enfermagem.

A eleição da NIC, como sistema padronizado de linguagem, foi fundamental para o processo de construção do instrumento, pois possibilitou categorizar seu conteúdo por meio de uma nomenclatura própria, reconhecida internacionalmente, que traduz um significado comum aos serviços de enfermagem no cenário nacional e internacional.

A utilização da NIC possibilitou, também, que fossem contempladas as diversas dimensões do cuidado, desde as dimensões fisiológicas às psicossociais, ampliando o conjunto de atividades desenvolvidas pela equipe de enfermagem.

A participação das enfermeiras especialistas, com ampla experiência profissional nas áreas assistencial, de ensino e de pesquisa, comprometidas com a construção do conhecimento nas áreas que envolveram a elaboração do instrumento, que compreendiam a importância e a necessidade do estudo e sua responsabilidade de ação, foi essencial para o aperfeiçoamento e para a validação aparente do conteúdo do instrumento. 
Ao grupo de especialistas coube analisar o conteúdo do instrumento quanto à clareza e à pertinência das atividades em relação aos domínios e classes; clareza na descrição das intervenções e atividades; indicação dos níveis crescentes das intervenções e atividades descritas, de acordo com o tempo estimado para sua realização; relevância das intervenções e atividades para a prática da assistência de enfermagem pediátrica; inclusão ou exclusão das atividades nas classes; inclusão ou exclusão de classes nos domínios; exclusão de algum domínio, bem como indicar se o instrumento proposto representa a prática assistencial de enfermagem pediátrica.

A análise dessas enfermeiras considerou que as intervenções e atividades selecionadas, para a composição do instrumento, são relevantes e representam a prática da assistência de enfermagem pediátrica.

Com a identificação das intervenções e atividades que representam a carga de trabalho da equipe de enfermagem, vislumbra-se o desenvolvimento de novas pesquisas, no sentido de realizar testes de confiabilidade e validade do instrumento, para verificar sua aplicabilidade na prática assistencial e gerencial, bem como correlacionar cada uma dessas intervenções e atividades com o tempo despendido para a sua realização, de forma a constituir um instrumento que determine a carga de trabalho da equipe de enfermagem das unidades pediátricas.

A complementação deste estudo representa, portanto, a possibilidade de instrumentalização das enfermeiras no que se refere à elaboração de propostas relacionadas ao quadro de pessoal de enfermagem com base nas necessidades específicas dos pacientes pediátricos, preenchendo a lacuna 
existente, atualmente, nessa área. Auxiliará, ainda, as enfermeiras, a identificarem a ocorrência do aumento ou diminuição de tempo consumido na assistência ao paciente pediátrico, permitindo uma distribuição mais eqüitativa de pessoal, aumento da produtividade, da eficiência e da eficácia da equipe. 


\section{REFERÊNCIAS}

1. Gaidzinski RR. O dimensionamento de pessoal de enfermagem em instituições hospitalares [tese livre-docência]. São Paulo (SP): Escola de Enfermagem da USP; 1998.

2. Gaidzinski RR, Fugulin FMT, Castilho V. Dimensionamento de pessoal de Enfermagem em Instituições de Saúde. In: Kurcgant $P$, editor.

Gerenciamento em enfermagem. Rio de Janeiro: Guanabara Koogan, 2005. Cap. 10, p.125-137.

3. Fugulin FMT. Dimensionamento de pessoal de enfermagem: avaliação do quadro de pessoal das unidades de internação de um hospital de ensino [tese]. São Paulo (SP): Escola de Enfermagem da USP; 2002.

4. Johnson M. Perspectives on costing nursing. Nurs Adm Q 1989; 1(14):6571.

5. Giovanetti P. Understanding patient classification systems. J Nurs Adm 1979; 9(2):4-9.

6. Gaidzinski RR. O dimensionamento do pessoal de enfermagem segundo a percepção de enfermeiras que vivenciam esta prática [tese]. São Paulo (SP): Escola de Enfermagem da USP; 1994.

7. Perroca MG. Instrumento de classificação de Perroca: validação clínica [tese]. São Paulo (SP): Escola de Enfermagem da USP; 2000.

8. Alward RR. Patient classification systems: the ideal vs reality. J Nurs Adm 1983; 13(2):14-9.

9. Wrona-Sexton S. Patient classification systems: another perspective. Nurs Manage 1992; 23(12):38-9.

10. Fugulin FMT, Gaidzinski RR, Kurcgant P. Sistema de classificação de pacientes: identificação do perfil assistencial dos pacientes das unidades de internação do HU-USP. Rev Latinoam Enfermagem 2005,13(1):72-8.

11. Connor RJ. Effettur use of nursing resources: a research report. Hospitals 1961; 35(5):30-9.

12. Bardan VZ, Schneider W. Matrix: a unique patient classification system. J Nurs Adm 1980; 10(12):25-31. 
13. Dijkers $M$, Paradise T. PCS: one system for both staffing and costing. Nurs Manage 1986; 17(1):25-34.

14. Wilson L, Prescott PA, Aleksandrowicz L. Nursing: a major hospital cost component. Health Serv Res 1988; 22(6):773-96.

15. Novaes HM. Padrões e indicadores de qualidade para hospitais. Brasil: OPAS; 1994.

16. Ribeiro CM. Sistema de classificação de pacientes como subsídio para provimento de pessoal de enfermagem [tese]. São Paulo (SP): Escola de Enfermagem da USP; 1972.

17. Willians $\mathrm{GH}$, Anderson JJ. Developing a labor and delivery patient classification systems. Nurs Manage 1992; 23(10):74-80.

18. Vaughan RG, Macleod V. Nurse staffing studies: to need to reinvent the wheel. J Nurs Adm 1980; 10(3):9-15.

19. Reinert $P$, Grant DR. A classification system to meet today's needs. J Nurs Adm 1981; 11(1):21-5

20. Alcalá MU, Nunes MF, Kato T, Reigada I, Silva RML, Yoshimura DK. Cálculo de pessoal: estudo preliminar para o estabelecimento de quadro de pessoal de enfermagem na superintendência médico hospitalar de urgência. São Paulo: Secretaria de Higiene e Saúde; 1982.

21. Alves SM, Gomes RMAA, Souza JMC, Azevedo BS, Passos FIP, Vieira NMACE. Enfermagem: contribuição para um cálculo de recursos humanos na área. Rio de Janeiro: Coordenadoria de Comunicação Social do INAMPS; 1988.

22. Fugulin FMT,Silva SHS, Shimizu HE, Campos FPF. Implantação do Sistema de Classificação de Pacientes na Unidade de Clinica Médica do Hospital Universitário de São Paulo. Rev. Med HU-USP 1994; 4(1/2):63-8.

23. Perroca MG. Sistema de classificação de pacientes: construção e validação de um instrumento [dissertação]. São Paulo (SP): Escola de Enfermagem da USP; 1996.

24. Ramos MLT, Bolomol E, Santos M, Barros CG, Ferreira NM, Silva MTA, et al. Sistema de classificação de pacientes por grau de dependência do cuidado de enfermagem: ENFSCORE. In: Anais do $4^{\circ}$ Encontro de Enfermagem e Tecnologia; 1994; São Paulo. São Paulo: ENFTEC; 1994. p.128-41. 
25. Romero EA, Araujo EA, Watanabe MY, Lisboa MAPLP, Abud MH, Santos NMB, et al. Proposta de um instrumento para classificação dos cuidados de enfermagem quanto ao grau de dependência. In: Anais do $4^{\circ}$ Encontro de Enfermagem e Tecnologia; 1994; São Paulo. São Paulo: ENFTEC; 1994. p.482-8.

26. Dias CN, Barbieri LL, Yashimoto LT, Roshing V. Informática no dimensionamento da equipe de enfermagem. In: Livro programa do $5^{\circ}$ Encontro de Enfermagem e Tecnologia; 1996; São Paulo. São Paulo: ENFTEC; 1996. p.125-9.

27. Martins EAP, Haddad MCL. Validação de um instrumento que classifica os pacientes em quatro graus de dependência do cuidado de enfermagem. Rev Latinoam Enfermagem 2000; 8(2):74-82.

28. Ayoub AC, Alves NRC, Silva YB. Sistema de classificação de paciente. In: Ayoub AC, Fontes ALC, Silva MAA, Alves NRC, Gigliote P, Silva YB. Planejando o cuidar na enfermagem oncológica. São Paulo: Lemar; 2000. p.15-27.

29. Dal Ben LW. Instrumento para dimensionar horas diárias de assistência de enfermagem residencial [dissertação]. São Paulo (SP): Escola de Enfermagem da USP; 2000.

30. Martins P. Sistema de Classificação de pacientes na especialidade enfermagem psiquiátrica [dissertação]. São Paulo, (SP): Escola de Enfermagem da USP; 2001.

31. Bochembuzio L. Instrumento para classificação de Recém-nascido de acordo com o grau de dependência [dissertação]. São Paulo (SP): Escola de Enfermagem da USP; 2002.

32. Conselho Federal de Enfermagem. Resolução n.189, de 25 de mar. de 1996. Estabelece parâmetros para dimensionamento do quadro de profissionais de enfermagem nas instituições de saúde. In: Conselho Regional de Enfermagem. Documentos básicos de enfermagem; enfermeiros, técnicos e auxiliares. São Paulo; 1997. p. 177-80.

33. Conselho Federal de Enfermagem. Resolução n. 293, de 21 de setembro de 2004. Fixa e estabelece parâmetros para dimensionamento do quadro de profissionais de enfermagem nas unidades assistenciais das instituições de saúde e assemelhados [online]. Rio de Janeiro: COREN; 2004. Disponível em: <http://corensp.org.br/072005> (27 jul. 2006). 
34. Commission d'Evaluation de la Sociéte de Réanimation de Langue Française. Utilisation de Lindice de gravité simpliflié et du systéme OMEGA. Réan Soins Intens Méd Urg 1986; (2):219-21.

35. Italian Multicenter Group of ICU Research (GIRTI). Time oriented score system (TOSS): a method for direct and qualitative assessment of nursing Work load for ICN patients. Intensive Care Med 1991; 17(6):340-5.

36. Miranda DR, Moreno R, Lapichino G. Nine Equivalents of nursing manpower use score (NEWS). Intensive Care Med 1997; 23(7): 760-5.

37. Cullen DJ, Civeta JM, Brggs BA, Ferrara LC. Therapeutic intervention scoring system: a method for quantitative comparison of patient care. Crit Care Med 1974; 2(2):57-60.

38. Miranda DR, Nap R, Rijk AD, Schaufeli W, Lapichino G. Nursing activities score. Crit Care Med 2003; 31(2):374-82.

39. Miranda DR, Rijk AD, Schaufeli W. Simplified therapeutic scoring system: the TISS-28 itens-results from a multicenter study. Crit Care Med 1996; 24(1):64-73.

40. Gaither N, Fraizer G. Administração da produção e operações. Trad. de José Carlos Barbosa dos Santos. $8^{\mathrm{a}}$ ed. São Paulo: Pioneira; 2001.

41. Queijo AF. Tradução para o português e validação de um instrumento de medida de carga de trabalho de enfermagem em Unidade de Terapia Intensiva: Nursing Activities Score (N.A.S.) [dissertação]. São Paulo (SP): Escola de Enfermagem da USP; 2002.

42. Conishi RMY. Avaliação do NAS - Nursing Activities Score - como instrumento de medida de carga de trabalho de enfermagem em UTI geral adulto [dissertação]. São Paulo (SP): Escola de Enfermagem da USP; 2005.

43. Georgieff MK, Mills MM, Bhatt P. Validation of two scoring systems which assess the degree of physiologic instability in critically ill newborn infants. Crit Care Med 1989; 17:17-21.

44. Pollack MM, Yeh TS, Ruttiman UE, Holbrook PR, Fields Al. Evaluation of pediatric intensive care. Crit Care Med 1984; 12(4):376-83.

45. Gray JE, Richardson DK, McCormick MD, Workman-Daniels K, Goldmann DA. Neonatal therapeutic intervention scoring system: a therapy-based severity-of-illness index. Pediatrics 1992; 90 (4):561-7. 
46. Polit D, Hungler BP. Fundamentos de pesquisa em enfermagem. $3^{\mathrm{a}}$ ed. Porto Alegre: Artes Médicas; 1995. Delineamento da pesquisa; p.107-40.

47. McCloskey JC, Bulechek GM. Classificação das Intervenções de Enfermagem. Trad. de Regina Machado Garcez. $3^{\mathrm{a}}$ ed. Porto Alegre: Artmed; 2004.

48. North American Nursing Diagnosis Association. Diagnósticos de enfermagem da NANDA: definições e classificação 2003-2004. Porto Alegre: Artmed; 2005.

49. Conselho Internacional de Enfermeiras. Classificação internacional para a prática de enfermagem Beta2. São Paulo: Conselho Internacional de Enfermagem; 2003.

50. Beyea SC. Standardized language: making nursing practice count. AORN J. 1999; 70(5):831-38.

51. Johnson M, Maas M, Moorhead S. Nursing outcomes classification (NOC). $2^{\text {nd }}$ ed. Saint-Louis: Mosby; 2000.

52. Polit DF, Hungler BP. Fundamentos da pesquisa em enfermagem. Trad. de Regina Machado Garcez. $3^{\mathrm{a}}$ ed. Porto Alegre: Artes Médicas; 1995.

53. Wood GL, Haber J. Pesquisa em enfermagem: métodos, avaliação crítica e utilização. $4^{\mathrm{a}}$ ed. Rio de Janeiro: Guanabara Koogan; 2001. 


\begin{abstract}
ANEXO A
CARTA-CONVITE PARA PARTICIPAÇÃO NA VALIDAÇÃO APARENTE DO ESTUDO: CONSTRUÇÃO DE UM INSTRUMENTO DE CLASSIFICAÇÃO DE PACIENTES PEDIÁTRICOS.
\end{abstract}

São Paulo, 1 junho de 2006.

Prezada Colega,

$\mathrm{Na}$ condição de mestranda do Programa de Pós-Graduação da Escola de Enfermagem da Universidade de São Paulo, na área de concentração Administração de Serviços de Enfermagem, estou desenvolvendo um estudo, sob a orientação da Profa Dra Fernanda Maria Togeiro Fugulin, com o objetivo de construir um instrumento para Classificação de Pacientes Pediátricos fundamentado Nursing Interventions Classification (NIC).

Por sua experiência e conhecimento nos temas envolvidos na construção do instrumento, gostaria de convidá-la para emitir seu julgamento sobre o conteúdo do mesmo.

A sua participação consistirá em avaliar cada item do instrumento, de acordo com as instruções de preenchimento do questionário anexo, o qual solicito que nos seja devolvido até dia 17/06/2006.

Se houver necessidade, espero contar com sua colaboração em outro momento para discussão e estabelecimento de consenso acerca das avaliações realizadas.

Certa de que sua contribuição em muito ampliará as possibilidades deste instrumento, agradeço antecipadamente sua disponibilidade.

Estou a disposição para eventuais esclarecimentos que se façam necessários.

Nanci Cristiano Santos

e-mail: nancics@hu.usp.br tel: 40091242 - res. tel. 92177436 - cel. 


\section{ANEXO B \\ TERMO DE CONSENTIMENTO LIVRE-ESCLARECIDO}

\section{Pesquisa: "CONSTRUÇÃO DE UM INSTRUMENTO DE CLASSIFICAÇÃO DE PACIENTES PEDIÁTRICOS"}

Pesquisadora: Nanci Cristiano Santos - CorenSP: 38127

Orientadora: Prof ${ }^{\mathrm{a}}$. Dr ${ }^{\mathrm{a}}$. Fernanda MariaTogeiro Fugulin - Docente da EEUSP.

Essa pesquisa está sendo desenvolvida para ser apresentada à Escola de Enfermagem da Universidade de São Paulo no Programa de pós graduação nível mestrado do Departamento de Administração em serviços de enfermagem.

O objetivo da pesquisa é a construção de um instrumento de classificação de pacientes pediátricos, para isso gostaria de contar com a sua opinião e experiência profissional na área pediátrica. Sua participação na pesquisa consiste em opinar sobre os itens que compõem o instrumento de classificação de pacientes pediátricos previamente construídos por mim para que possa ter o seu conteúdo melhor elaborado.

Sua participação é voluntária, sendo que não haverá nenhum tipo de sanção ou prejuízo, caso se recuse a participar, ou decida-se, a qualquer momento desistir de participar. As informações serão tratadas de forma anônima e sigilosa.

$\mathrm{Eu}$, declaro que, após convenientemente esclarecido pelo pesquisador e ter entendido o que me foi explicado, consinto em participar da pesquisa.

São Paulo,

Assinatura da Enfermeira

Assinatura do pesquisador

Tel: 3039-9278 HU-Ped

Res: (011) 4009-1242

Cel: 9217-7436 


\section{ANEXO C \\ APRESENTAÇÃO E INSTRUÇÕES PARA PREENCHIMENTO DO QUESTIONÁRIO}

O Sistema de Classificação de Pacientes (SCP) constitui-se em um instrumento gerencial que possibilita estimar as necessidades diárias dos pacientes em relação à assistência de enfermagem, contribuindo dessa forma, para a determinação da carga de trabalho da equipe de enfermagem e, consequentemente, para o processo de tomada de decisão relacionado à previsão, alocação e avaliação de recursos humanos. Diante da inexistência de instrumentos de classificação de pacientes pediátricos, optamos pela construção de um instrumento que contemple a especificidade e as necessidades assistenciais destes pacientes.

Para a construção do instrumento, julgamos necessária a utilização de um sistema padronizado de linguagem, próprio da enfermagem, que pudesse comunicar um mesmo significado aos diversos locais de atendimento e, também, auxiliar no aperfeiçoamento da prática assistencial e gerencial da enfermagem.

Neste sentido, o instrumento foi construído com base na Nursing Interventions Classification (NIC), cuja estrutura taxonômica é constituída por três níveis, o primeiro nível é representado por sete domínios, o segundo constituído por 30 classes, organizadas dentro dos domínios e o terceiro nível é representado por 486 intervenções de enfermagem, agrupadas de acordo com as classes e os domínios.

As intervenções de enfermagem da NIC são constituídas pelos seguintes elementos: título, definição e uma lista de atividades, que descrevem as ações de profissionais ao executar a intervenção de enfermagem.(McCloskey; Bulechek, 2002). O titulo e a definição, por constituírem uma linguagem padronizada, não podem ser modificadas, a não ser por um processo formal de revisão; as atividades podem ser modificadas de acordo com a necessidade de uma situação particular do paciente, proporcionando a individualização do cuidado.

Para a construção do presente instrumento foi realizada, inicialmente, leitura e compreensão do significado de cada domínio, das classes relacionadas nos domínios, das intervenções incluídas em cada classe e das atividades relacionadas em cada intervenção. Passou-se então à seleção das atividades consideradas de maior relevância na prática assistencial de enfermagem pediátrica para comporem o instrumento.

Após seleção das atividades, estas foram inseridas na classe e conseqüentemente no domínio a qual melhor se caracterizava de acordo com a definição da classe. Concluída esta etapa as atividades foram descritas de acordo com a linguagem técnica-científica utilizada na prática, em vários níveis de acordo com a complexidade crescente de assistência de enfermagem, levando-se em consideração o tempo gasto e o número de profissionais envolvidos na sua realização.

No instrumento construído foram preservadas as nomenclaturas utilizadas pela NIC sendo constituído por cinco domínios representados por números e por 20 classes representadas por letras. As classes selecionadas foram incluídas no instrumento no domínio correspondente contendo a definição da NIC. Embora as intervenções tenham subsidiado a seleção das atividades, elas não fazem parte do instrumento que foi constituído somente por domínios, classes e atividades.

As atividades que solicitamos a você referem-se à:

1. Avaliação da descrição de cada atividade quanto à clareza e objetividade;

2. Avaliação de cada atividade quanto à pertinência para a prática da assistência de enfermagem pediátrica; 
3. Avaliação de cada atividade quanto ao nível de complexidade crescente dos itens;

4. Avaliação das atividades quanto à pertinência ao domínio e classe onde foram inseridas no instrumento;

5. Comentários e sugestões sobre a inclusão ou exclusão de classes, domínios e atividades.

Para cada pergunta você deverá selecionar uma das opções e poderá utilizar o espaço discriminado para sugestões e comentários, caso julgue pertinente.

Nanci Cristiano Santos

e-mail: nancics@hu.usp.br tel: 40091242 - res.

tel. 92177436 - cel. 


\title{
ANEXO D \\ Questionário sobre o Instrumento de Classificação de Pacientes Pediátricos
}

\author{
Domínio 1: FISIOLóGıco BÁsıco \\ Cuidados que dão suporte ao funcionamento físico do organismo
}

\section{Classe A : ConTROLE dA ATIVIDADE E EXERcício}

Intervenções para organizar ou auxiliar a atividade física e a conservação e gasto de energia (NIC; 2004). Incluem atividades relacionadas à deambulação e à movimentação.

A1 Sem limitação de atividades físicas atividades realizadas de forma independente.

A2 Deambulação/movimentação auxiliada pelo acompanhante ou repouso no leito controlado pelo acompanhante, nas 24 horas, sob a supervisão da equipe de enfermagem.

A3 Repouso no leito controlado pela equipe de enfermagem; deambulação/ movimentação auxiliadas por um profissional de enfermagem.

A4 Movimentação/deambulação realizada por 2 ou mais profissionais da equipe de enfermagem.

1.1 As atividades descritas são pertinentes a este domínio? $\square$ SIM $\square$ NÃO Comentários/sugestões

1.2 As atividades descritas são pertinentes a esta classe? $\square$ SIM $\square$ NÃO

Comentários/sugestões

1.3 Há clareza na descrição das atividades? $\square$ SIM $\square$ NÃO

Comentários/sugestões

1.4 As atividades indicam nível crescente de complexidade assistencial?

૫ SIM $\square$ NÃO

Comentários/sugestões

1.5 As atividades descritas são relevantes para a prática da assistência de enfermagem pediátrica? $\square$ SIM $\square$ NÃO

Comentários/sugestões

1.6 Você incluiria alguma atividade nesta classe? $\square$ SIM $\square$ NÃO

Comentários

1.7 Você excluiria alguma atividade nesta classe? $\square$ SIM $\square$ NÃO

Comentários 


\section{Classe B: CONTROLE DAS ELIMINAÇÕES}

Intervenções para estabelecer e manter padrões de eliminação intestinal e urinária normais e controlar complicações resultantes de padrões alterados (NIC; 2004). Incluem atividades relacionadas ao uso de vaso sanitário/comadre/urinol; troca de fraldas; higiene perineal; controles da freqüência, volume, consistência, cor, odor das eliminações intestinais e urinárias; cuidados com sondas e drenos; sondagem vesical intermitente ou de demora; cuidados com ostomia.

B1 Uso do vaso sanitário realizado de forma independente.

B2 Uso do vaso sanitário/comadre/urinol ou troca de fraldas e higiene perineal auxiliadas/realizadas pelo acompanhante, nas 24 horas, sob a supervisão da equipe de enfermagem.

B3 Uso do vaso sanitário/comadre/urinol ou troca de fraldas e higiene perineal auxiliadas/realizadas por um profissional da equipe de enfermagem, até 6 vezes em 24 horas, ou sondagem vesical de demora nas últimas 24 horas.

B4 Uso do vaso sanitário/comadre/urinol ou troca de fraldas e higiene perineal auxiliadas/realizadas por um profissional da equipe de enfermagem mais que 6 vezes em 24 horas.

B5 Controle de volume das eliminações através de urinol/peso de fraldas/saco coletor/sondas ou sondagem vesical intermitente, realizadas pela equipe de enfermagem.

2.1 As atividades descritas são pertinentes a este domínio? $\square$ SIM $\square$ NÃO Comentários/sugestões

2.2 As atividades descritas são pertinentes a esta classe? $\square$ SIM $\square$ NÃO Comentários/sugestões

\subsection{Há clareza na descrição das atividades? $\square$ SIM $\square$ NÃO}

Comentários/sugestões

2.4 As atividades indicam nível crescente de complexidade assistencial? $\square$ SIM $\square$ NÃO

Comentários/sugestões

2.5 As atividades descritas são relevantes para a prática da assistência de enfermagem pediátrica? $\square$ SIM $\square$ NÃO

Comentários/sugestões

2.6 Você incluiria alguma atividade nesta classe? $\square$ SIM $\square$ NÃO

Comentários

2.7 Você excluiria alguma atividade nesta classe? $\square$ SIM $\square$ NÃO

Comentários 


\section{Classe C: CONTROLE DA IMOBILIDADE}

Intervenções para controlar a restrição de movimentos corporais e as seqüelas (NIC; 2004). Incluem atividades como: mudança de decúbito, transporte, transferência de cama/cadeira/carrinho; cuidados com aparelho de gesso e trações; utilização de mecanismos para posicionamento.

C1 Mudança de decúbito, transporte, transferência do leito auxiliada/realizada pelo acompanhante, nas 24 horas, sob a supervisão da equipe de enfermagem.

C2 Mudança de decúbito/transporte/transferência do leito; cuidados com tração/gesso; exercícios ativos e passivos de amplitude de movimentos, utilização de mecanismos para posicionamento adequado, auxiliadas/realizadas por um profissional da equipe de enfermagem.

C3 Mudança de decúbito programadas/transporte/transferência do leito; cuidados com tração/gesso, realizadas por 2 ou mais profissionais da equipe de enfermagem, em qualquer freqüência.

3.1 As atividades descritas são pertinentes a este domínio? $\square$ SIM $\square$ NÃO

Comentários/sugestões

3.2 As atividades descritas são pertinentes a esta classe? $\square$ SIM $\square$ NÃO

Comentários/sugestões

3.3 Há clareza na descrição das atividades? $\square$ SIM $\square$ NÃO

Comentários/sugestões

3.4 As atividades indicam nível crescente de complexidade assistencial? $\square$ SIM $\square$ NÃo

Comentários/sugestões

3.5 As atividades descritas são relevantes para a prática da assistência de enfermagem pediátrica? $\square$ SIM $\square$ NÃO

Comentários/sugestões

3.6 Você incluiria alguma atividade nesta classe? $\square$ SIM $\square$ NÃO

Comentários

3.7 Você excluiria alguma atividade nesta classe? $\square$ SIM $\square$ NÃO

Comentários 


\section{Classe D: SUPORTE NUTRICIONAL}

Intervenções para modificar ou manter o estado nutricional (NIC; 2004). Incluem atividades relacionadas à administração de dietas; monitoração da aceitação, da tolerância e da restrição alimentar e controle de peso.

D1 Por via oral de forma independente alimentação/hidratação.

D2 Alimentação/hidratação por via oral (incluindo seio materno e mamadeira) auxiliada/oferecida pelo acompanhante, nas 24 horas, sob supervisão da equipe enfermagem. Controle do peso diário; da aceitação alimentar/hídrica realizada pela equipe de enfermagem.

D3 Alimentação/hidratação por via oral (incluindo mamadeira e copinho) auxiliada/oferecida pela equipe de enfermagem e controle do peso diário, da aceitação e da tolerância alimentar/hídrica realizado pela equipe de enfermagem.

D4 Administração da alimentação/hidratação por sondas; controle de peso diário; controle da restrição alimentar/hídrica realizado pela equipe de enfermagem.

D5 Administração da alimentação/hidratação por via oral para paciente com alteração do padrão de sucção e/ou deglutição; nutrição parenteral; controle de peso 2 vezes ao dia, realizado pela equipe de enfermagem.

4.1 As atividades descritas são pertinentes a este domínio? $\square$ SIM $\square$ NÃO

Comentários/sugestões

4.2 As atividades descritas são pertinentes a esta classe? $\square$ SIM $\square$ NÃO

Comentários/sugestões

4.3 Há clareza na descrição das atividades? $\square$ SIM $\square$ NÃO

Comentários/sugestões

4.4 As atividades indicam nível crescente de complexidade assistencial? $\square$ SIM $\square$ NÃO

Comentários/sugestões

4.5 As atividades descritas são relevantes para a prática da assistência de enfermagem pediátrica? $\square$ SIM $\square$ NÃO

Comentários/sugestões

4.6 Você incluiria alguma atividade nesta classe? $\square$ SIM $\square$ NÃO

Comentários

4.7 Você excluiria alguma atividade nesta classe? $\square$ SIM $\square$ NÃO

Comentários 


\section{Classe D: SUPORTE NUTRICIONAL}

Intervenções para modificar ou manter o estado nutricional (NIC; 2004). Incluem atividades relacionadas à administração de dietas; monitoração da aceitação, da tolerância e da restrição alimentar e controle de peso.

D1 Por via oral de forma independente alimentação/hidratação.

D2 Alimentação/hidratação por via oral (incluindo seio materno e mamadeira) auxiliada/oferecida pelo acompanhante, nas 24 horas, sob supervisão da equipe enfermagem. Controle do peso diário; da aceitação alimentar/hídrica realizada pela equipe de enfermagem.

D3 Alimentação/hidratação por via oral (incluindo mamadeira e copinho) auxiliada/oferecida pela equipe de enfermagem e controle do peso diário, da aceitação e da tolerância alimentar/hídrica realizado pela equipe de enfermagem.

D4 Administração da alimentação/hidratação por sondas; controle de peso diário; controle da restrição alimentar/hídrica realizado pela equipe de enfermagem.

D5 Administração da alimentação/hidratação por via oral para paciente com alteração do padrão de sucção e/ou deglutição; nutrição parenteral; controle de peso 2 vezes ao dia, realizado pela equipe de enfermagem.

5.1 As atividades descritas são pertinentes a este domínio? $\square$ SIM $\square$ NÃO

Comentários/sugestões

5.2 As atividades descritas são pertinentes a esta classe? $\square$ SIM $\square$ NÃO

Comentários/sugestões

5.3 Há clareza na descrição das atividades? $\square$ SIM $\square$ NÃO

Comentários/sugestões

5.4 As atividades indicam nível crescente de complexidade assistencial? $\square$ SIM $\square$ NÃo Comentários/sugestões

5.5 As atividades descritas são relevantes para a prática da assistência de enfermagem pediátrica? $\square$ SIM $\square$ NÃO

Comentários/sugestões

5.6 Você incluiria alguma atividade nesta classe? $\square$ SIM $\square$ NÃO

Comentários

5.7 Você excluiria alguma atividade nesta classe? $\square$ SIM $\square$ NÃO

Comentários 


\section{Classe F: FACILITAÇÃO DO AUTOCUIDADO}

Intervenções para proporcionar ou auxiliar nas atividades de rotina de vida diária (NIC, 2004). Incluem atividades para promover, restaurar ou capacitar o próprio paciente de acordo com a faixa etária ou o cuidador para assumir o autocuidado (banho, higiene oral), cuidados com períneo.

F1 Banho no chuveiro, troca de roupas, higiene oral e higiene íntima, sono e repouso,- realizada adequadamente, de forma independente.

F2 Banho no chuveiro, troca de roupas, higiene oral e higiene íntima, sono e repouso auxiliada/realizada pelo acompanhante, nas 24 horas, sob supervisão da equipe de enfermagem.

F3 Banho no chuveiro, banheira ou cadeira; troca de roupas, higiene oral e higiene íntima, e auxílio para o sono e repouso auxiliada/realizada pelo acompanhante, com orientação e acompanhamento da equipe de enfermagem.

F4 Banho de chuveiro, banheira ou cadeira; troca de roupas; higiene oral e higiene íntima; auxílio para o sono e repouso, realizado por um profissional da equipe de enfermagem.

F5 Banho na incubadora ou no leito, troca de roupas, higiene oral, higiene íntima e auxílio para o sono e repouso, realizado por um profissional da equipe de enfermagem.

F6 Banho no leito, higiene oral e higiene íntima realizado por dois ou mais profissionais da equipe de enfermagem.

6.1 As atividades descritas são pertinentes a este domínio? $\square$ SIM $\square$ NÃO Comentários/sugestões

6.2 As atividades descritas são pertinentes a esta classe? $\square$ SIM $\square$ NÃO Comentários/sugestões

6.3 Há clareza na descrição das atividades? $\square$ SIM $\square$ NÃO

Comentários/sugestões

6.4 As atividades indicam nível crescente de complexidade assistencial? SIM $\square$ NÃO

Comentários/sugestões

6.5 As atividades descritas são relevantes para a prática da assistência de enfermagem pediátrica? $\square$ SIM $\square$ NÃO

Comentários/sugestões

6.6 Você incluiria alguma atividade nesta classe? $\square$ SIM $\square$ NÃO

Comentários

6.7 Você excluiria alguma atividade nesta classe? $\quad \square$ SIM $\square$ NÃO

Comentários 


\begin{abstract}
Domínio 2: FISIOLÓGıCO COMPLEXO
Cuidados que dão suporte à regulação homeostática.

Classe G: CONTROLE DE ELETRÓLITOS E ÁCIDO-BÁsıco

Intervenções para regular o equilíbrio eletrolítico/ Ácido-básico e prevenir complicações (NIC; 2004). Incluem atividades relacionadas à monitoração e coleta de exames laboratoriais; monitoração de sintomas de alcalose/acidose metabólica e respiratória.

G1 Verificação e controle de glicosúria/cetonúria/glicemia capilar, realizados pela equipe de enfermagem.

G2 Verificação e monitoração dos níveis de eletrólitos e gases sanguíneos, realizados pela equipe de enfermagem.

G3 Administração de terapia de reidratação oral, realizados pela equipe de enfermagem.

G4 Realização de procedimentos dialíticos, realizados pela equipe de enfermagem.

7.1 As atividades descritas são pertinentes a este domínio? $\square$ SIM $\square$ NÃO Comentários/sugestões
\end{abstract}

7.2 As atividades descritas são pertinentes a esta classe? $\square$ SIM $\square$ NÃO Comentários/sugestões

7.3 Há clareza na descrição das atividades? $\square$ SIM $\square$ NÃO

Comentários/sugestões

7.4 As atividades indicam nível crescente de complexidade assistencial? SIM $\square$ NÃO

Comentários/sugestões

7.5 As atividades descritas são relevantes para a prática da assistência de enfermagem pediátrica? $\square$ SIM $\square$ NÃO

Comentários/sugestões

7.6 Você incluiria alguma atividade nesta classe? $\square$ SIM $\square$ NÃO

Comentários

7.7 Você excluiria alguma atividade nesta classe? $\square$ SIM $\square$ NÃO

Comentários 


\section{Classe H: CONTROLE DE DROGAS}

Intervenções para facilitar efeitos desejados de agentes farmacológicos (NIC; 2004). Atividades que incluem: punção e manutenção de acesso venoso, cuidados na administração e controle de medicamentos.

\begin{tabular}{|l|l|}
\hline H1 & $\begin{array}{l}\text { Administração de medicamentos via oral ou inalatória, com colaboração do } \\
\text { paciente/acompanhante. }\end{array}$ \\
\hline H2 & $\begin{array}{l}\text { Administração de medicamentos por sondas ou pelas vias IM/ID/SC com } \\
\text { colaboração do paciente/acompanhante. }\end{array}$ \\
\hline H3 & $\begin{array}{l}\text { Punção de acesso venoso e/ou administração de medicamentos } \\
\text { endovenosos contínuos ou intermitentes, com colaboração do } \\
\text { paciente/acompanhante. }\end{array}$ \\
\hline H4 & $\begin{array}{l}\text { Punção de acesso venoso periférico ou administração de medicamentos, por } \\
\text { qualquer via, com resistência do paciente, realizado por mais de um } \\
\text { profissional. }\end{array}$ \\
\hline H5 & $\begin{array}{l}\text { Administração de medicação endovenosa por via central ou por via periférica, } \\
\text { com necessidade de múltiplas punções nas 24hs, por dificuldade de acesso } \\
\text { ou de manutenção. }\end{array}$ \\
\hline H6 & $\begin{array}{l}\text { Administração de drogas vasoativas e ou quimioterápicos e/ou passagem de } \\
\text { cateter central de inserção periférica, realizado pelo enfermeiro. }\end{array}$ \\
\hline 8.1 As atividades descritas são pertinentes a este domínio? $\square$ SIM $\square$ NÃO \\
Comentários/sugestões
\end{tabular}

\subsection{As atividades descritas são pertinentes a esta classe? $\square$ SIM $\square$ NÃO} Comentários/sugestões

\subsection{Há clareza na descrição das atividades? $\square$ SIM $\square$ NÃO Comentários/sugestões}

8.4 As atividades indicam nível crescente de complexidade assistencial? $\square$ SIM $\square$ NÃO

Comentários/sugestões

8.5 As atividades descritas são relevantes para a prática da assistência de enfermagem pediátrica? $\square$ SIM $\square$ NÃO

Comentários/sugestões

\subsection{Você incluiria alguma atividade nesta classe? $\square$ SIM $\square$ NÃO}

Comentários

\subsection{Você excluiria alguma atividade nesta classe? $\square$ SIM $\square$ NÃO} Comentários 


\begin{tabular}{|c|c|}
\hline \multicolumn{2}{|r|}{$\begin{array}{l}\text { Classe I: CONTROLE NEUROLóGıco } \\
\text { Intervenções para otimizar as funções neurológicas (NIC, 2004). Incluem } \\
\text { atividades como: Monitorização do nível de consciência, orientação, reações a } \\
\text { estímulos, aplicação de escala de Coma de Galsgow, monitoração da pressão de } \\
\text { perfusão cerebral e pressão intracraniana. }\end{array}$} \\
\hline 11 & $a^{\prime}$ \\
\hline 12 & $\begin{array}{l}\text { Observação de sinais e sintomas de hipoatividad } \\
\text { acompanhante, nas } 24 \text { horas, orientado e super } \\
\text { enfermagem. }\end{array}$ \\
\hline 13 & 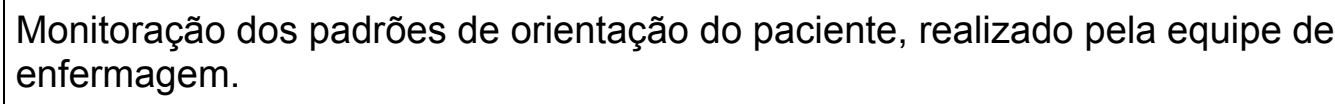 \\
\hline 14 & 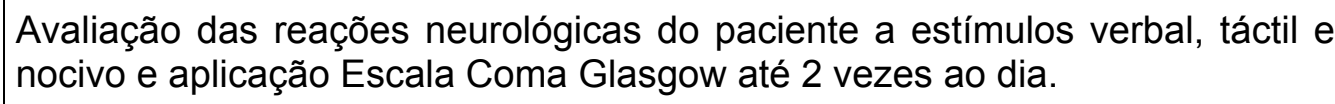 \\
\hline 15 & nitoração da pressão de perfusão \\
\hline & $\mathbf{M} \square \mathbf{N}$ \\
\hline
\end{tabular}

9.2 As atividades descritas são pertinentes a esta classe? $\square$ SIM $\square$ NÃO Comentários/sugestões

9.3 Há clareza na descrição das atividades? $\square$ SIM $\square$ NÃO Comentários/sugestões

9.4 As atividades indicam nível crescente de complexidade assistencial? $\square$ SIM $\square$ NÃO

Comentários/sugestões

9.5 As atividades descritas são relevantes para a prática da assistência de enfermagem pediátrica? $\square$ SIM $\square$ NÃO

Comentários/sugestões

9.6 Você incluiria alguma atividade nesta classe? $\quad \square$ SIM $\square$ NÃO

Comentários

9.7 Você excluiria alguma atividade nesta classe? $\square$ SIM $\square$ NÃO Comentários 


\begin{tabular}{|c|c|}
\hline & lacion \\
\hline K1 & éreas \\
\hline K2 & m 24 \\
\hline K3 & $\begin{array}{l}\text { (catéter, tenda, } \\
\text { ais que } 3 \text { vezes }\end{array}$ \\
\hline K4 & $\begin{array}{l}\text { Administração de oxigênio por Ventilação Mecânica invasiva (tubo } \\
\text { endotraqueal) ou não invasiva (CPAP, BIPAP), com aspirações da } \\
\text { cânula/vias áreas em qualquer freqüência. }\end{array}$ \\
\hline & ritas são pertinentes a este domínio? \\
\hline
\end{tabular}

10.2 As atividades descritas são pertinentes a esta classe? $\square$ SIM $\square$ NÃO Comentários/sugestões

\begin{tabular}{l}
\hline 10.3 Há clareza na descrição das atividades? \\
Comentários/sugestões
\end{tabular}

10.5 As atividades descritas são relevantes para a prática da assistência de enfermagem pediátrica? $\square$ SIM $\square$ NÃO

Comentários/sugestões

10.6 Você incluiria alguma atividade nesta classe? $\square$ SIM $\square$ NÃO

Comentários

10.7 Você excluiria alguma atividade nesta classe? $\square$ SIM $\square$ NÃO

Comentários 


\section{Classe L: Controle dA PeLe/ Lesões}

Intervenções para manter ou restaurar a integridade tissular (NIC; 2004). Atividades como: prevenção de lesões e úlceras de pressão; cuidados com locais de incisões cirúrgicas, lesões e ostomias; cuidados na amputação, realização de curativos e monitorização da evolução da lesão.

L1 Limpeza da ferida ou incisão cirúrgica realizada durante o banho pelo paciente/acompanhante.

L2 Utilização de colchões especiais ou acessórios no leito, realização de massagem para prevenção de úlcera de pressão; curativo de lesão, incisão cirúrgica, ostoma, local de inserção de sonda, dreno, cateter, realizada 1 vez ao dia, pela equipe de enfermagem.

L3 Curativo de lesão, incisão cirúrgica, ostoma, local de inserção de sonda, dreno, cateter, realizada 2 vezes ao dia, pela equipe de enfermagem.

L4 Curativo realizado pela enfermagem 3 ou mais vezes ao dia ou curativo de múltiplas lesões, eviscerações ou lesão de grande extensão (queimaduras), realizada pela equipe de enfermagem, em qualquer freqüência, que utilizem mais que 40 minutos para sua realização.

11.1 As atividades descritas são pertinentes a este domínio? $\quad \square$ SIM $\square$ NÃO
Comentários/sugestões

11.2 As atividades descritas são pertinentes a esta classe? $\square$ SIM $\square$ NÃO Comentários/sugestões

11.3 Há clareza na descrição das atividades? $\quad \square$ SIM $\square$ NÃO
Comentários/sugestões

11.4 As atividades indicam nível crescente de complexidade assistencial? $\square$ SIM $\square$ NÃO

Comentários/sugestões

11.5 As atividades descritas são relevantes para a prática da assistência de enfermagem pediátrica? $\square$ SIM $\square$ NÃO

Comentários/sugestões

11.6 Você incluiria alguma atividade nesta classe? $\square$ SIM $\square$ NÃO

Comentários

11.7 Você excluiria alguma atividade nesta classe? $\square$ SIM $\square$ NÃO

Comentários 


\section{Classe M: TERMO REGULAÇÃo}

Intervenções para manter a temperatura corporal dentro dos parâmetros normais (NIC; 2004). Incluem atividades como controle de temperatura corporal, de incubadora, berço aquecido; aplicação de compressas quentes e frias.

M1 Monitoração da temperatura corpórea, realizado pela equipe de enfermagem, até 3 vezes ao dia.

M2 Monitoração da temperatura corpórea realizada pela equipe de enfermagem, mais que 3 vezes ao dia.

M3 Aplicação de compressas frias ou quentes, realização de banho de imersão para regulação da temperatura corporal em algum período, realizada pela equipe de enfermagem.

M4 Monitoração contínua da temperatura corpórea e/ou utilização e controle de equipamentos (incubadora, berço aquecido, colchões para aquecimento e resfriamento) para manutenção/regulação da temperatura corporal, realizada pela equipe de enfermagem.

12.1 As atividades descritas são pertinentes a este domínio? $\quad \square$ SIM $\square$ NÃO
Comentários/sugestões

12.2 As atividades descritas são pertinentes a esta classe? $\square$ SIM $\square$ NÃO Comentários/sugestões

\subsection{Há clareza na descrição das atividades? $\quad \square$ SIM $\square$ NÃO}

Comentários/sugestões

12.4 As atividades indicam nível crescente de complexidade assistencial? $\square$ SIM $\square$ NÃO

Comentários/sugestões

12.5 As atividades descritas são relevantes para a prática da assistência de enfermagem pediátrica? $\square$ SIM $\square$ NÃO

Comentários/sugestões

12.6 Você incluiria alguma atividade nesta classe? $\square$ SIM $\square$ NÃO

Comentários

12.7 Você excluiria alguma atividade nesta classe? $\square$ SIM $\square$ NÃO

Comentários 


\section{Classe N: CONTROLE dA PERfUSÃo TISSULAR}

Intervenções para otimizar a circulação do sangue e líquidos aos tecidos, (NIC; 2004). Incluem atividades como: Monitoração de sinais e sintomas de sangramentos; reposição rápida de líquidos; administração de hemoderivados; aplicação de terapia compressiva e bolsa de gelo no local do sangramento.

N1 Administração de líquidos para manutenção da volemia por via endovenosa; monitoração de sinais e sintomas de sangramento, realizada pela equipe de enfermagem.

N2 Administração rápida de líquidos por via endovenosa ou intra-óssea para reposição da volemia, realizada pela equipe de enfermagem.

N3 Monitoração da pressão venosa central, pressão arterial média, perfusão periférica e pressão capilar pulmonar, realizada pela equipe de enfermagem.

N4 Administração de hemoderivados; cuidados com aparelhos de suporte circulatório mecânico; inserção de Cateter Central de Inserção Periférica, realizado pelo enfermeiro nas últimas 24 horas.

13.1 As atividades descritas são pertinentes a este domínio?
Comentários/sugestões

13.2 As atividades descritas são pertinentes a esta classe? $\square$ SIM $\square$ NÃO Comentários/sugestões

13.3 Há clareza na descrição das atividades? $\quad \square$ SIM $\square$ NÃO

Comentários/sugestões

13.4 As atividades indicam nível crescente de complexidade assistencial?

$\square$ SIM $\square$ NÃO

Comentários/sugestões

13.5 As atividades descritas são relevantes para a prática da assistência de enfermagem pediátrica? $\square$ SIM $\square$ NÃO

Comentários/sugestões

13.6 Você incluiria alguma atividade nesta classe? $\square$ SIM $\square$ NÃO

Comentários

13.7 Você excluiria alguma atividade nesta classe? $\square$ SIM $\square$ NÃO Comentários

14. Você incluiria ou excluiria alguma classe no domínio 2: Fisiológico Complexo $\square$ SIM $\square$ NÃO

Qual(is)?Comente: 


\begin{tabular}{l}
\hline Domínio 3: COMPORTAMENTAL \\
Cuidados que dão suporte ao funcionamento psicosocial e facilitam mudanças no \\
estilo de vida. \\
\hline Classe O: TERAPIA COMPORTAMENTAL \\
Intervenções para reforçar ou promover comportamentos desejáveis ou alterar \\
comportamentos indesejáveis (NIC; 2004 ). Incluem atividades como observação do \\
comportamento; estabelecimento de limites; acompanhamento em atividades \\
lúdicas/recreativas; utilização do brinquedoterapêutico; ensino de habilidades \\
sociais adequadas; acompanhamento na abstinência de álcool e drogas.
\end{tabular}

15.2 As atividades descritas são pertinentes a esta classe? $\square$ SIM $\square$ NÃO Comentários/sugestões

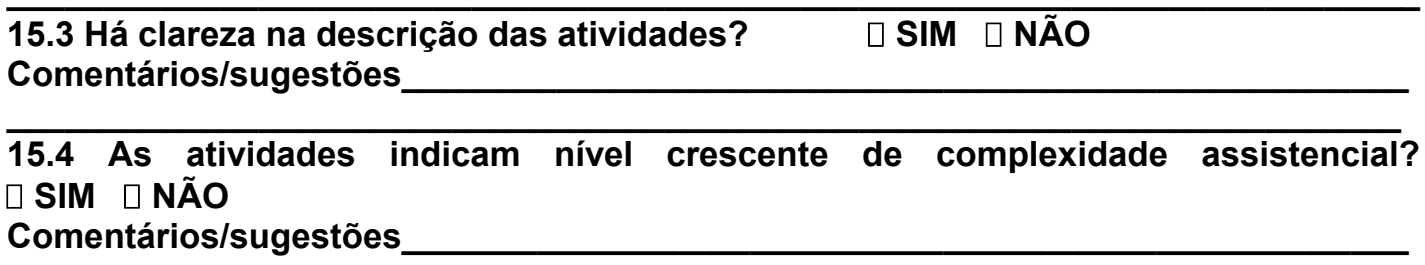

15.5 As atividades descritas são relevantes para a prática da assistência de enfermagem pediátrica? $\square$ SIM $\square$ NÃO

Comentários/sugestões

15.6 Você incluiria alguma atividade nesta classe? $\square$ SIM $\square$ NÃO

Comentários

15.7 Você excluiria alguma atividade nesta classe? $\square$ SIM $\square$ NÃO

Comentários 


\begin{abstract}
Classe R: ASSISTÊNCIA NO ENFRENTAMENTO
Intervenções para auxiliar o outro a contar com seus pontos fortes,adaptar-se a uma mudança de função ou alcançar um nível mais elevado de funcionamento, (NIC; 2004). Incluem atividades como: informação, orientação, esclarecimento de dúvidas e apoio nas situações de estresse.

R1 Orientação sobre procedimento/tratamento específico, prestada ao paciente/família por profissional da equipe de enfermagem.

R2 Encaminhamento do paciente/família aos serviços de apoio social/espiritual, realizado por profissional da equipe de enfermagem.

R3 Esclarecimento à cerca de diagnóstico/tratamento/prognóstico médico, prestado ao paciente/família pelo enfermeiro.

R4 Participação do enfermeiro em reuniões com paciente/família/equipe multidisciplinar para informação, tomada de decisão, soluções de problemas evidenciados durante a internação e adaptação à mudança em algum período.

R5 Permanência de um profissional da equipe de enfermagem junto ao paciente/família durante períodos de ansiedade e/ou fases de sofrimento.

16.1 As atividades descritas são pertinentes a este domínio? $\quad \square$ SIM $\square$ NÃO Comentários/sugestões
\end{abstract}

16.2 As atividades descritas são pertinentes a esta classe? $\square$ SIM $\square$ NÃO Comentários/sugestões

16.3 Há clareza na descrição das atividades? $\quad \square$ SIM $\square$ NÃO

Comentários/sugestões

16.4 As atividades indicam nível crescente de complexidade assistencial? प SIM $\square$ NÃO

Comentários/sugestões

16.5 As atividades descritas são relevantes para a prática da assistência de enfermagem pediátrica? $\square$ SIM $\square$ NÃO

Comentários/sugestões

16.6 Você incluiria alguma atividade nesta classe? $\square$ SIM $\square$ NÃO

Comentários

16.7 Você excluiria alguma atividade nesta classe? $\square$ SIM $\square$ NÃO

Comentários

17. Você incluiria ou excluiria alguma classe no domínio 3: Comportamental

Qual(is)?Comente:

$$
\square \text { SIM } \quad \text { NÃO }
$$




\begin{tabular}{|c|c|}
\hline Dor & $\begin{array}{l}\text { ínio 4: SEGURANÇA } \\
\text { ados que dão suporte à proteção contra danos }\end{array}$ \\
\hline $\begin{array}{l}\text { U - } \\
\text { Inte } \\
\text { fisio } \\
\text { urgé } \\
\text { cáro }\end{array}$ & $\begin{array}{l}\text { CONTROLE DE CRISE } \\
\text { venções para oferecer ajuda imediata, a curto prazo, em crises psicológicas e } \\
\text { ógicas (NIC, 2004). Incluem atividades relacionadas aos procedimentos de } \\
\text { ncia e emergência como: atendimento na crise convulsiva, reanimação } \\
\text { iorespiratória e cardioversão. }\end{array}$ \\
\hline U1 & $\begin{array}{l}\text { Auxílio da equipe de enfermagem em procedimentos de urgência/emergência } \\
\text { como intubação, drenagem de tórax, passagem de cateter, inserção de } \\
\text { marca passo, cirurgia de urgência/emergência, nas últimas } 24 \text { horas. }\end{array}$ \\
\hline U2 & $\begin{array}{l}\text { Atendimento prestado pela equipe de enfermagem em crise convulsiva nas } \\
\text { últimas } 24 \text { horas. }\end{array}$ \\
\hline U3 & $\begin{array}{l}\text { Auxílio da equipe de enfermagem em cirurgia de urgência/emergência e/ou } \\
\text { participação da equipe de enfermagem em reanimação cardiorespiratória e } \\
\text { cardioversão, nas últimas } 24 \text { horas. }\end{array}$ \\
\hline & $\begin{array}{l}\text { As atividades descritas são pertinentes a este domínio? } \\
\text { entários/sugestões. }\end{array}$ \\
\hline & $\begin{array}{l}\text { As atividades descritas são pertinentes a esta classe? } \square \text { SIM } \square \text { NÃO } \\
\text { entários/sugestões }\end{array}$ \\
\hline & $\begin{array}{l}\text { Há clareza na descrição das atividades? } \\
\text { entários/sugestões. }\end{array}$ \\
\hline & $\begin{array}{l}\text { As atividades indicam nível crescente de complexidade assistencial? } \\
\text { M } \quad \text { NÃO } \\
\text { entários/sugestões }\end{array}$ \\
\hline & $\begin{array}{l}\text { As atividades descritas são relevantes para a prática da assistência de } \\
\text { rmagem pediátrica? } \quad \square \text { SIM } \square \text { NÃO } \\
\text { entários/sugestões }\end{array}$ \\
\hline $\begin{array}{l}18 . \\
\text { Co }\end{array}$ & $\begin{array}{l}\text { Você incluiria alguma atividade nesta classe? } \square \text { SIM } \square \text { NÃO } \\
\text { entários. }\end{array}$ \\
\hline & $\begin{array}{l}\text { ocê excluiria alguma atividade nesta classe? } \square \text { SIM } \square \text { NÃO } \\
\text { ntários. }\end{array}$ \\
\hline
\end{tabular}




\begin{tabular}{|c|c|}
\hline \multicolumn{2}{|r|}{$\begin{array}{l}\text { V - CONTROLE DE RIScos } \\
\text { Intervenções para iniciar a atividade de redução de riscos e manter a } \\
\text { monitorização contínua de riscos (NIC; 2004). Incluem atividades como: } \\
\text { monitorização de sinais vitais; atividades relacionadas à prevenção de quedas, } \\
\text { fuga, alucinações; contenção física; controle de alergia e controle de infecção. }\end{array}$} \\
\hline V1 & $\begin{array}{l}\text { onitorização de FR, FC e PA realizada pela enfermagem até } 3 \text { vezes ao } \\
\text { a: observação do paciente e/ou adoção de medidas para prevenir queda, } \\
\text { ga e suicídio, realizada pela enfermagem. }\end{array}$ \\
\hline V2 & e do p \\
\hline V3 & $\begin{array}{l}\text { e/ou } \\
\text { cídio; } \\
\text { enfermagem. }\end{array}$ \\
\hline & $\begin{array}{l}\text { tividades descritas são pertinentes a este domínio? } \\
\text { rios/sugestões }\end{array}$ \\
\hline
\end{tabular}

19.2 As atividades descritas são pertinentes a esta classe? $\square$ SIM $\square$ NÃO Comentários/sugestões

19.3 Há clareza na descrição das atividades? $\square$ SIM $\square$ NÃO Comentários/sugestões

19.4 As atividades indicam nível crescente de complexidade assistencial? $\square$ SIM $\square$ NÃO

Comentários/sugestões

19.5 As atividades descritas são relevantes para a prática da assistência de enfermagem pediátrica? $\square$ SIM $\square$ NÃO

Comentários/sugestões

19.6 Você incluiria alguma atividade nesta classe? $\square$ SIM $\square$ NÃO

Comentários

19.7 Você excluiria alguma atividade nesta classe? $\square$ SIM $\square$ NÃO Comentários

20. Você incluiria ou excluiria alguma classe no domínio 4: Segurança

$\square$ SIM $\quad$ NÃO

Qual (is) ?Comente: 


\begin{tabular}{|c|c|}
\hline & $\begin{array}{l}\text { io 6: SISTEMA DE SAÚDE } \\
\text { los que dão suporte ao uso eficaz do sistema de atendimento à saúde }\end{array}$ \\
\hline & $\begin{array}{l}\text { IAÇÃo COM O SISTEMA DE SAÚDE } \\
\text { nções para facilitar a interface entre paciente/família e o sistema de } \\
\text { nento à saúde (NIC; 2004). Incluem atividades como; orientação, } \\
\text { nento e visita domiciliária para o autocuidado no domicílio. }\end{array}$ \\
\hline $\mathrm{Y1}$ & $\begin{array}{l}\text { Orientação ao paciente/cuidador para a realização de atividades de } \\
\text { autocuidado no domicílio prestada por profissional da equipe de enfermagem } \\
\text { em algum período. }\end{array}$ \\
\hline $\mathrm{Y} 2$ & $\begin{array}{l}\text { Orientação e treinamento do paciente/cuidador para realização de atividade } \\
\text { de autocuidado no domicilio realizado pelo enfermeiro em algum período. }\end{array}$ \\
\hline Y3 & $\begin{array}{l}\text { Visita domiciliária, realizada pelo enfermeiro, para adequação do ambiente } \\
\text { quanto as necessidades do paciente em relação as atividades de } \\
\text { autocuidado. }\end{array}$ \\
\hline & $\begin{array}{l}\text { atividades descritas são pertinentes a este domínio? } \\
\text { tários/sugestões. }\end{array}$ \\
\hline & $\begin{array}{l}\text { atividades descritas são pertinentes a esta classe? } \square \text { SIM } \square \text { NÃO } \\
\text { tários/sugestões }\end{array}$ \\
\hline & $\begin{array}{l}\text { clareza na descrição das atividades? } \\
\text { ários/sugestões }\end{array}$ \\
\hline
\end{tabular}

21.4 As atividades indicam nível crescente de complexidade assistencial? $\square$ SIM $\square$ NÃO

Comentários/sugestões

21.5 As atividades descritas são relevantes para a prática da assistência de enfermagem pediátrica? $\square$ SIM $\square$ NÃO Comentários/sugestões

21.6 Você incluiria alguma atividade nesta classe? $\square$ SIM $\square$ NÃO Comentários

21.7 Você excluiria alguma atividade nesta classe? $\square$ SIM $\square$ NÃO Comentários 


\begin{tabular}{|c|c|}
\hline \multicolumn{2}{|r|}{$\begin{array}{l}\text { a - CONTROLE DO SISTEMA DE SAÚDE } \\
\text { Intervenções para proporcionar e melhorar os serviços de apoio ao ofereciment } \\
\text { de cuidados (NIC; 2004). Incluem atividades relacionadas com assistência en } \\
\text { exames em consultas, acompanhamento de estudantes e funcionários; solicitaçãc } \\
\text { e avaliação de novos produtos; conferencia de medicação controlada e discussã } \\
\text { de caso clínico. }\end{array}$} \\
\hline \multicolumn{2}{|r|}{ Auxílin e acomnanhamento de um nrofissional da equine de enfermagem } \\
\hline a2 & $\begin{array}{l}\text { Conferência e reposição de medicamento controlado utilizado pelo paciente } \\
\text { realizado pelo enfermeiro, em algum período. }\end{array}$ \\
\hline a3 & $\begin{array}{l}\text { Solicitação e avaliação de novos produtos/equipamentos para utilização do } \\
\text { paciente, feita pelo enfermeiro; participação do enfermeiro em discussões } \\
\text { acerca de alteração no estado do paciente. }\end{array}$ \\
\hline a4 & $\begin{array}{l}\text { Preparo e acompanhamento de profissional de enfermagem ou estudante } \\
\text { para realização de atividade específica com o paciente, realizado pelo } \\
\text { enfermeiro em algum período. }\end{array}$ \\
\hline a5 & $\begin{array}{l}\text { Acompanhamento de paciente a outra instituição para realização de } \\
\text { exames/consultas em algum período }\end{array}$ \\
\hline
\end{tabular}

22.1 As atividades descritas são pertinentes a este domínio? $\quad \square$ SIM $\square$ NÃO Comentários/sugestões

22.2 As atividades descritas são pertinentes a esta classe? $\square$ SIM $\square$ NÃO Comentários/sugestões

22.3 Há clareza na descrição das atividades? $\quad \square$ SIM $\square$ NÃO Comentários/sugestões

22.4 As atividades indicam nível crescente de complexidade assistencial? $\square$ SIM $\square$ NÃO

Comentários/sugestões

22.5 As atividades descritas são relevantes para a prática da assistência de enfermagem pediátrica? $\square$ SIM $\square$ NÃO

Comentários/sugestões

22.6 Você incluiria alguma atividade nesta classe? $\square$ SIM $\square$ NÃO

Comentários

22.7 Você excluiria alguma atividade nesta classe? $\square$ SIM $\square$ NÃO

Comentários 
b - CONTROLE DAS INFORMAÇÕES: intervenções para facilitar a comunicação sobre os cuidados de saúde (NIC-2004). Incluem atividades de documentação, discussão de caso, reuniões para avaliação de cuidados multidisciplinares, transcrição de prescrições, encaminhamentos, coleta de dados de pesquisa, passagem de plantão, consulta e orientação por telefone.

b1 Realização de exame físico/diagnóstico/evolução e prescrição de enfermagem pelo enfermeiro 1 vez ao dia, monitoração dos registros realizados pela equipe de enfermagem no prontuário do paciente

b2 Participação de profissional de enfermagem na implementação de protocolos de pesquisa a serem desenvolvidos com o paciente (orientação, coleta de material) em algum período.

b3 Elaboração de relatórios sobre incidentes/ocorrências, encaminhamentos a outros profissionais ou instituições.

b4 Elaboração de relatórios sobre o paciente para outros profissionais ou instituições, preenchimento de impresso para notificação de eventos adversos com o paciente.

\begin{tabular}{l}
$\left.\begin{array}{l}\text { 23.1 As atividades descritas são pertinentes a este domínio? } \\
\text { Comentários/sugestões }\end{array}\right]$ SIM $\square$ NÃO \\
\hline
\end{tabular}

23.2 As atividades descritas são pertinentes a esta classe? $\square$ SIM $\square$ NÃO Comentários/sugestões

23.3 Há clareza na descrição das atividades? $\quad \square$ SIM $\square$ NÃO
Comentários/sugestões

23.4 As atividades indicam nível crescente de complexidade assistencial? $\square$ SIM $\square$ NÃO

Comentários/sugestões

23.5 As atividades descritas são relevantes para a prática da assistência de enfermagem pediátrica? $\quad$ SIM $\square$ NÃO Comentários/sugestões

23.6 Você incluiria alguma atividade nesta classe? $\square$ SIM $\square$ NÃO Comentários

23.7 Você excluiria alguma atividade nesta classe? $\square$ SIM $\square$ NÃO Comentários: 
25.Você excluiria algum (s) domínio no instrumento? $\square$ SIM $\square$ NÃO Qual (is)?

Comente:

26. Na sua opinião o instrumento proposto representa a prática assistencial de enfermagem pediátrica?

Comentários/sugestões $\square$ SIM $\square$ NÃO 


\title{
ANEXO E \\ Aprovação do projeto pela COMEP-HU
}

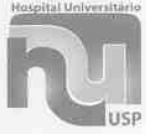

São Paulo, 16 de dezembro de 2005.

$I^{m o(a)} \cdot S^{r(a)}$

Dra. Fernanda Maria Togeiro Fugulin

Departamento de Orientação Profissional

Escola de Enfermagem

UNIVERSIDADE DE SÃO PAULO

REFERENTE: Projeto de Pesquisa "Construção de instrumento de classificação de pacientes pediátricos" - Registro CEP: 614/05

Prezado(a) Senhor(a)

O Comitê de Ética em Pesquisa do Hospital Universitário da Universidade de São Paulo, em reunião ordinária realizada no dia 16 de dezembro de 2005, analisou o projeto de pesquisa acima citado, considerando-o como APROVADO, bem como, seu Termo de Consentimento Livre e Esclarecido.

Lembramos que cabe ao pesquisador elaborar e apresentar a este Comitê, relatórios anuais (parciais ou final, em função da duração da pesquisa), de acordo com a Resolução 196/96 do Conselho Nacional de Saúde, item IX.2 letra c.

O primeiro relatório está previsto para 16 de dezembro de 2006.

Atenciosamente,

\author{
le $2 c$ \\ Dra. Maria Teresalzulini da Costa \\ Coordenadora \\ Comitê de Ética em Pesquisa - CEP-HU/USP
}




\section{ANEXO F \\ CARTA-CONVITE PARA PARTICIPAÇÃO EM REUNIÃO DE CONSENSO}

São Paulo, 30 de junho de 2006.

Prezada Colega,

Agradecemos sua disponibilidade e colaboração na avaliação do instrumento de classificação de pacientes pediátricos, proposto pela mestranda Nanci Cristiano Santos. Suas sugestões e comentários muito contribuíram para a reestruturação do instrumento, que foi modificado, de acordo com as considerações do grupo de especialistas.

As principais modificações referiram-se à:

o instrumento passou a ser denominado "Instrumento para identificação da carga de trabalho de pacientes pediátricos", uma vez que essa denominação melhor caracteriza sua finalidade;

- $\quad$ as atividades e intervenções descritas após a definição de cada classe foram retiradas por tornarem-se repetitivas, já que estão descritas nos diferentes níveis de complexidade;

- $\quad$ as descrições de todas as atividades que compõem os diferentes itens do instrumento foram revisadas no sentido de obter maior clareza e objetividade, bem como padronizar um estilo de redação que indicasse a carga de trabalho da equipe de enfermagem e não o perfil assistencial do paciente;

- $\quad$ alguns níveis de complexidade foram excluídos, acrescentados ou aglutinados, considerando sua representatividade na carga de trabalho da equipe (tempo despendido para sua realização);

- $\quad$ a classe $\mathrm{E}$ foi ampliada de forma a contemplar novas atividades;

Não foram incluídos ou excluídos domínios ou classes.

Estamos enviando, em anexo, o instrumento com as modificações apontadas, solicitando, novamente, sua colaboração no sentido de reavaliá-lo.

Gostaríamos, ainda, de contar com sua presença em uma reunião, agendada conforme sua disponibilidade, para que possamos esclarecer eventuais dúvidas e realizar novas adequações que sejam consideradas necessárias.

Atenciosamente,

Nanci Cristiano Santos

e-mail: nancics@hu.usp.br tel: 40091242 - res. tel. 92177436 - cel. 


\section{AUTORIZAÇÃO}

Autorizo a reprodução e/ou divulgação total ou parcial da presente obra, por meio convencional ou eletrônico, desde que seja citada a fonte.

Nome da Autora: Nanci Cristiano Santos

Assinatura:

Instituição: Hospital Universitário

Local: Universidade de São Paulo

Endereço: Av. Prof. Lineu Prestes, 2565

Email: nancics@hu.usp.br 